\title{
Best practice in psychological activities in cardiovascular prevention and rehabilitation: Position Paper
}

\author{
Marinella Sommaruga1, Elisabetta Angelino², Paola Della Porta3, Mara Abatello4, \\ Giacomo Baiardo5, Gianluigi Balestroni6, Ornella Bettinardi7, Edward Callus, \\ Chiara Ciraci9, Ombretta Omodeo10, Claudia Rizza11, Paolo Michielin12, \\ Marco Ambrosetti13, Raffaele Griffo ${ }^{14}$, Roberto F.E. Pedretti ${ }^{15}$, Antonia Pierobon ${ }^{16}$
}

\author{
1 Psychology Unit, Istituti Clinici Scientifici Maugeri IRCCS, Milan \\ 2 Psychology Unit, Istituti Clinici Scientifici Maugeri IRCCS, Turin \\ 3 Psychologist at FERB Onlus Rehabilitation Center of Cernusco sul Naviglio, Milan \\ 4 Unit of Cardiology, University Health Agency, Trieste \\ 5 Cardiovascular Institute of Camogli, Genova \\ 6 Psychology Unit, Istituti Clinici Scientifici Maugeri IRCCS, Veruno \\ 7 Department of Mental Health and Addictive Behavior, Local Health Authority, Piacenza \\ 8 Clinical Psychology Service, Polyclinic San Donato IRCCS, San Donato Milanese, Milan \\ 9 Cardiovascular Prevention and Rehabilitation Unit, Don Carlo Gnocchi Foundation, Parma \\ 10 Psychology Unit, Istituti Clinici Scientifici Maugeri IRCCS, Pavia \\ 11 Gruppo Multimedica Spa-IRCCS, Milan \\ 12 Department of Psychology, University of Padua \\ 13 Cardiovascular Rehabilitation Unit, Le Terrazze Clinic, Cunardo \\ 14 Research and Educational Centre GICR-IACPR, Genoa \\ 15 Department of Cardiology, Istituti Clinici Scientifici Maugeri IRCCS, Pavia \\ 16 Psychology Unit, Istituti Clinici Scientifici Maugeri IRCCS, Montescano, Italy
}

\begin{abstract}
Recent guidelines on cardiovascular disease prevention suggest multimodal behavioral interventions for psychosocial risk factors and referral for psychotherapy in the case of clinically significant symptoms of depression and anxiety overall. Accordingly, psychologists of the Italian Association for Cardiovascular Prevention, Rehabilitation and Epidemiology (GICR-IACPR) have reviewed the key components of psychological activities in cardiovascular prevention and rehabilitation (CPR). The aim of this study was to elaborate a position paper on the
\end{abstract}

Corresponding author: Marinella Sommaruga, Psychology Unit, Istituti Clinici Scientifici Maugeri IRCCS, Via Camaldoli 64, 20138 Milan, Italy. E-mail: marinella.sommaruga@icsmaugeri.it

Key words: Best practice; psychology; psychotherapy; cardiovascular rehabilitation; cardiac diseases; prevention.

Received for publication: 16 May 2018

Accepted for publication: 10 June 2018

(C) Copyright M. Sommaruga et al., 2018

Tipografia PI-ME Editrice, Italy

Monaldi Archives for Chest Disease 2018; 88:966

doi: 10.4081/monaldi.2018.966

This article is distributed under the terms of the Creative Commons Attribution Noncommercial License (by-nc 4.0) which permits any noncommercial use, distribution, and reproduction in any medium, provided the original author(s) and source are credited. best practice in routine psychological activities in CPR based on efficacy, effectiveness and sustainability.

The steps followed were: i) a review of the latest international guidelines and position papers; ii) analysis of the evidence-based literature; iii) a qualitative analysis of the psychological services operating in some reference Italian cardiac rehabilitation facilities; iv) classification of the psychological activities in CPR as low or high intensity based on the NICE Guidelines on psychological interventions on anxiety and depression.

We confirm the existence of an association between depression, anxiety, social factors, stress, personality and illness onset/outcome and coronary heart disease. Evidence for an association between depression, social factors and disease outcome emerges particularly for chronic heart failure. Some positive psychological variables (e.g., optimism) are associated to illness outcome. Evidence is reported on the impact of psychological activities on 'new' conditions which are now indicated for cardiac rehabilitation: pulmonary hypertension, grown-up congenital heart, endstage heart failure, implantable cardioverter-defribrillator and mechanical ventricular assist devices, frail and oldest-old patients, and end-oflife care. We also report evidence related to caregivers. The Panel divided evidence-based psychological interventions into: i) low intensity (counseling, psycho-education, self-care, self-management, telemedicine, selfhelp); or ii) high intensity (individual, couples and/or family and group psychotherapy, such as stress management). The results show that psychotherapy is consisting of cognitive-behavioral therapy (mainly), interpersonal therapy, and short term psycho-dinamic therapy.

The current data further refine the working tools available for psychological activities in CPR, giving clear directions about the choice of interventions, which should be evidence-based and have at least a minimum standard. This document provides a comprehensive update on new knowledge and new paths for psychologists working in the CPR settings. 


\section{Introduction}

The aim of this position paper is to serve as a tool for consultation in order to promote best practice (based on effectiveness, efficiency and sustainability) in the daily clinical activity of psychologists working in the Cardiovascular Prevention and Rehabilitation (CPR) setting. Since the publication in 2003 of the "Guidelines for psychology activities in cardiologic rehabilitation and prevention" [1] there has been a constant growth both in the number of psychological interventions performed in the real-world of CPR [2] and in the publication of articles, meta-analyses and systematic reviews [3-8] on the association between heart disease, psychological variables and psychological interventions. Therefore, the need has emerged to update the knowledge not only as regards the traditional indications for CPR interventions coronary heart disease (CHD), chronic heart failure (CHF) and cardiac surgery - but also concerning psychological activities in other scenarios of cardiovascular disease (CVD) where the indication for rehabilitation treatment has emerged more recently, such as pulmonary hypertension, grown-up congenital heart (GUCH), end-stage heart failure, use of implantable cardioverter-defribrillator and mechanical ventricular assist devices, frail and older/oldest patients, and end-of-life care. This document also includes an analysis of family/caregivers and their specific need for psychological interventions: in fact, numerous reports in the literature [9] now show the positive effects of good family and social support on CVD outcome in terms of better adherence and reduced readmissions, particularly in elderly patients who are increasingly referred to CPR programs and for whom the importance of a neuropsychological evaluation is also stressed.

A special feature of this paper is the introduction of a low/high intensity grade for classifying the psychological interventions, in line with the NICE guidelines on psychological interventions for anxiety and depression disorders [10]. In the nineties, in fact, the "stepped care" model was introduced [11] which envisaged the planning of clinical psychology and psychotherapy interventions at different levels of intensity and complexity (low or high) according to the results of the initial assessments carried out [12]. In 2007, the British government approved the "Improving Access to Psychological Therapies" (IAPT) Program [13] to facilitate the access of people with common emotional disorders to evidence-based psychological treatments (Care Services Improvement Partnership, 2007). This program is characterized by three steps, the first of which is related to psy- chological evaluation and eventual monitoring over time; the second consists of low-intensity interventions suitable for patients with less severe disorders and/or of recent onset, such as education, counseling, relaxation techniques, and self-help groups; the third provides for more severe patients with high-intensity interventions, mainly psychotherapeutic treatments. The extensive and now widespread application of the IAPT model has confirmed its appropriateness, effectiveness and efficiency [14-16].

The low/high intensity classification allows the psychologist to identify and select, based on scientific evidence, interventions that can be adapted to different patients, different organizational regimes (hospitalization, day hospital, outpatient) and to the time available (full-time, part-time, or consultant psychologist). The IAPT treatment pathway is self-correcting in the sense that, if a patient with sub-threshold symptoms deteriorates over time or does not gain benefit from low-intensity treatments, he/she will go on to high-intensity treatments.

\section{Methods}

The criteria used to elaborate this position paper on best practice were based on:

- consultation of the latest international guidelines and consensus statements produced by the major scientific societies;

- identification of a reference bibliography based on evidence of effectiveness through a search of the most well-known databases (Cochrane Library, Medline, PsychINFO [2005-2017];

- qualitative analysis of the psychological services offered in some reference cardiac rehabilitation facilities.

We did not examine in this document the psychological approach and treatments for addictions and sexuality, for which the reader should refer to the relative guidelines.

In presenting the evidence for the association between psychological variables and disease manifestation/outcome and/or for the association between psychological variables and clinical condition, the strength of evidence is graded as strong, moderate, or mild. "Onset" of a disease is defined as its occurrence, while the term 'outcome' refers to its clinical trend (new events, mortality). For each pathology, after a brief discussion, we provide a synthesis of the evidence of the associations between psychological variables and disease and of the psychological interventions.

The evidence-based interventions are divided into two levels according to the NICE model [10] (Table 1).

Table 1. Evidence based interventions divided into two levels according to the NICE model.

\begin{tabular}{l} 
Low intensity = interventions of low complexity performed by the psychologist and/or in collaboration \\
with the multidisciplinary team: \\
- Individual and/or group counseling (from single interview to motivational interview) \\
\hline - Psycho-educational sessions regarding psychosocial risk factors, smoking, diet, etc. \\
\hline - Multidisciplinary sessions regarding information and management (self-care, self-management, self-help) \\
\hline - Self-help groups \\
- Use of self-help manuals \\
- Distance information and treatment programs, using the Internet \\
- Relaxation training \\
- Problem solving training \\
High intensity = interventions of high complexity performed by the psychologist and/or in collaboration \\
with the multidisciplinary team: \\
- Psychotherapy interventions: individual, group (stress management) or family (at least 1/week) \\
- Multidisciplinary interventions (evidence of the need to implement a structured psychotherapeutic intervention \\
(cognitive-beavioral therapy, motivational, mindfulness, etc.)
\end{tabular}




\section{Coronary heart disease}

A large body of empirical research shows that psychosocial risk factors, such as low socio-economic status, social isolation, stress, type-D personality, depression and anxiety increase the risk of incident CHD and also contribute to poorer health-related quality of life and prognosis in patients with established CHD. Psychosocial risk factors may also act as barriers to lifestyle changes and treatment adherence [4-6]. Based on epidemiological data, Rozanski recently divided the behavioral risk factors for CHD into five broad categories:

a. Physical health behaviors, including physical inactivity, poor diet and obesity, smoking, poor or inadequate sleep, inadequate rest and relaxation

b. Negative emotions and mental mindsets including depressive symptoms, anxiety, pessimism, anger and hostility

c. Chronic stress, including situational stressors (work stress, marital stress, social stressors, caregiver strain, childhood and adult abuse, medical illness), and perceived stress

d. Social isolation and poor social support

e. Lack of sense of purpose.

Whilst psychosocial risk factors such as anxiety and depression can affect the cardiovascular system through biological and behavioral pathways, conversely CHD and its treatments can induce anxious and depressive reactions in the patient and caregiver. Depression disorder prevalence is between 15 and 20\% in CHD and estimates of clinically-relevant depressive symptoms are much higher [17,18]. A recent meta-analysis indicated a $16 \%$ rate of prevalence of anxiety disorders [19]. Recently, Pedersen et al. [20] have provided a general overview of the prevalence of selected psychosocial risk factors, their impact on patient-reported and clinical outcomes, and biological and behavioral mechanisms that may explain the association between psychosocial factors and health outcomes.

\section{STRONG EVIDENCE}

\section{- Behavioral risk factors}

○ Physical inactivity, unhealthy diet, smoking [6]

- Sleep disorders [21,22]

- Inadequate rest and relaxation [4]

- Consumption of 3 or more alcohol beverages per day [6]. Data are contrasting, however, regarding the moderate consumption of alcohol: positive association [23]; negative association [24,25]

- Use of cocaine (associated with increased cardiovascular risk, e.g. tachycardia, arrhythmias, hypertension and vasospasm of the coronary arteries) [26].

\section{- Social factors}

○ Low socio-economic status, measured by educational and professional level, income, and perceived working position [27-32]. In particular, individuals after acute myocardial infarction (AMI) with low income and low education are at risk of premature mortality [33].

○ Lack of social support [31,34]. Epidemiological studies have shown that a reduced social network, poor social support and/or its perception increase the risk of cardiac events [4]. The significant role of the various social factors has been confirmed by a recent meta-analysis of 148 studies [35]. Conversely, a good social integration was associated with an almost 2 -fold increase in survival.

- Clinical depression and depressive symptoms

Both major depression and depressive symptoms increase the risk of developing CHD and its worsening once the disease is manifest: a review of 54 studies in fact documented an approximately 2 -fold increase in risk in both primary and secondary prevention [36]. Depression is especially deleterious to cardiovascular prognosis post-AMI [17] and there does not appear to be a significant difference in prognosis between persons with pre-existing depression and those developing depression post-AMI [37].

Also the syndrome known as "vital exhaustion" increases the risk of new events [38,39].

\section{- Anxiety and panic}

In recent years the role of anxiety as a CHD risk factor has been clarified. Several meta-analyzes have identified an increased risk associated with anxiety symptoms both in population and in patient cohorts [40,41].

Recent studies have shown that the risk of CHD events is high among patients with generalized anxiety disorder $[42,43]$.

Among the anxiety disorders, evidence implicates generalised anxiety disorder with poorer CHD prognosis in a recent metaanalysis [44).

\section{- Stress}

It is widely documented that acute stress (mourning, natural disasters, terrorist attacks, football matches) can act as triggers of acute coronary syndrome [45,46]. More complex is the analysis of chronic stress related to specific situations:

○ Psychosocial characteristics of work. The association between work stress and cardiovascular events has been further documented over the course of time. Numerous studies [47-50] have demonstrated that high demands combined with low work control produce stress, and in a recent meta-analysis a 1.23-fold increase was reported in incidence of CHD in association with job strain [48], compared with a 1.63-fold increase in mortality associated with unemployment [51].

- Separation and divorce. Separation and divorce are another common stressor that increase the risk of mortality; some epidemiological studies also suggest an association between marital tension and coronary events [4].

○ Negative childhood experiences. Regarding negative childhood experiences, a large longitudinal study [52] showed that women with severe childhood abuse had an approximately 1.5 -fold greater risk of early onset of cardiac events.

- Stress associated with disease. Diseases in themselves constitute a stress factor, often leading to depression, anxiety, social isolation and loss of self-esteem. In particular, the perception of stress can also be an important determinant of health $[53,54]$.

\section{- Post-traumatic stress disorder (PTSD)}

Studies have reported the prevalence of post-AMI stress disorder and PTSD to be as high as 30\% [55], although a meta-analysis of 24 observational cross-sectional studies estimated the prevalence to be $12 \%$ [56]. In any case, the rate of PTSD is much higher in cardiac patients than in the general population (10-12\% in men and $5-6 \%$ in women) [57].

These patients may be prone to develop re-experiencing (e.g., recalling the cardiac event or defibrillator shocks, dreams of cardiac arrest, flashbacks of the medical intervention and surgical procedure), avoidance (e.g., avoiding reminders of the cardiac event such as the location of the event, the hospital, medication, situations in which heart rate increases such as exercise or sexual activity), and arousal symptoms (e.g., preoccupation with heart rate or chest pain, insomnia) [58].

\section{MODERATE EVIDENCE}

\section{- Personality factors}

- Anger and hostility. Over the years it has been confirmed that there is no association between type A personality and 
coronary disease onset/outcome. A meta-analysis [59] confirmed that anger and hostility are associated with increased risk of cardiovascular events both in the healthy population and in coronary patients. However, the association is less than that observed for depression and anxiety.

- Type D personality. A type D personality is present in about one-third of patients with CHD [60] and predicts a poorer prognosis [61-63], although some recent studies [64,65] have shown contrasting results. Type D is also associated with worsening of functional capacity and health status [66].

\section{- Positive psychological variables}

The role played by positive emotions (positive affect) in the development of CHD is increasingly the subject of scientific research, although it is still not completely clear [67]. Empirical evidence suggests that there is an association between positive affective states and health outcomes, including cardiovascular risk reduction and an increased resistance to infection [68]. Positive affectivity according to Steptoe [68] may be part of a broader profile of psycho-social resilience that reduces the risk of adverse outcomes of physical health.

Positive psychosocial factors also promote physiological effects, such as improvements in immune, endothelial, and autonomic functions $[69,70]$. Optimism is associated with a higher experience of positive emotions, enhanced social functioning, and better recovery from myocardial infarction and cardiac procedures. Recent epidemiological studies have shown that pessimism increases the risk for cardiac events, stroke and/or all-cause mortality, whereas optimism exerts a buffering role [71-74].

\section{MILD EVIDENCE}

Some studies document different psychological profiles in relation to gender and age, and there are growing data in the literature underlining the importance of psychosocial risk factors for the development of CHD in women [75-80] (Table 2).

In summary, in the opinion of the Panel, from the literature analysis there emerges:

- strong evidence of an association between the following variables and onset/outcome of the disease:

- Behavioral risk factors

- Social factors

- Depression

- Anxiety and panic

- Stress

- Post-traumatic stress disorder

- moderate evidence of an association between the following variables and onset/outcome of the disease:

- Personality factors

- Positive psychological variables

\section{PSYCHOLOGICAL INTERVENTIONS}

The position papers and psychological guidelines underline the need for an effective management of these psychosocial risk factors, including screening of psychosocial risk factors and implementation of different psychological interventions programs such as counseling, motivational interviews, health psycho-education and psychotherapy.

Pogosova et al. [5] suggest the need for core competencies that should include a screen for stress and psychosocial risk factors to identify clinically relevant levels of depression, anxiety, anger/hostility, relationship stress and low social support. It may be more important to teach patients how to change their existing stressors, or enhance their coping mechanisms for existing stressors, rather than to change unhealthy lifestyle habits. Therefore, it is essential to identify stressors with the patients and support them in finding ways to attenuate these stressors. This ideally should be carried out by trained personnel in dedicated sessions dealing with stress [5].

Rozanski [4] suggests some evidence-based techniques developed as management strategies for promoting healthy behaviors and the enhancement of psychosocial well-being, many of which are derived from Cognitive Behavioral Therapy (CBT): health counseling, smoking cessation, weight management, self monitoring, stress management, etc. A large number of "multidisciplinary" studies have been conducted to determine the effectiveness of psychosocial interventions for primary and secondary prevention but often the effects of the psychosocial components cannot be formally isolated from these studies.

The studies on psychological interventions for CHD patients have reported positive effects on quality of life, health behavior, and somatic risk profile, while others reported a protective effect on morbidity and mortality [3]. Some studies showed small-to-moderate improvements in depression and anxiety, a small reduction in cardiac mortality risk [81] and a reduction in all-cause mortality risk for men, but not for women [82]. Men appear to profit more from the interventions than women, but less studies have been performed on women than men. In particular, the meta-analysis by Whalley et al. [81] underlined the positive effects of psychological interventions on quality of life, depressive symptoms and anxiety, as well as an effect on cardiac mortality. Linden et al. [82] showed that programs which were initiated at least two months after the cardiac event showed stronger effects on the rate of future events than those initiated immediately after.

Welton et al. [83] carried out systematic literature searches to update an earlier Cochrane review and classified components of interventions into 6 types: usual care, educational, behavioral, cognitive, relaxation, and support. Most interventions were a combination of these components. There was some evidence that psychological interventions were effective in reducing total cholesterol and standardized mean anxiety scores, that interventions with behavioral components were effective in reducing the odds ratio of all-cause mortality and nonfatal AMI, and that interventions with behavioral and/or cognitive components were associated with reduced standardized mean depression scores.

Table 2. Evidence of association between the following variables and onset/outcome of CHD in women.

- depression [Ye S et al. 2012, Low et al. 2010, Shanmugasegaram S et al. 2012, Doeringet LV 2011, Möller- Leimkühler 2008]

- anxiety disorder [Doering 2011, Low et al. 2010]

- repressed anger [Low et al. 2010]

- low social support [Möller-Leimkühler 2008]

- stress associated with family relationships or responsibility [Low et al. 2010, Georgiades A 2009]

In women, general anxiety, hostility and work-related stress are less frequently associated with CHD [Low et al. 2010]

Women report more stressful life events and other psychosocial risk factors in the year following discharge [Georgiades 2009] 
Pogosova et al. [5] affirmed that stress management should be offered to patients (on an individual basis or in small groups) and that significant others should be included in the programs.

In a systematic review, Dickens et al. [84] sought to identify the characteristics of psychological interventions that improve depression and depressive symptoms among people with CHD. The results show that psychological interventions improved depression, although the effect was small. Problem solving, general education, skills training, CBT and relaxation had small effects on CHD patients, who were recruited irrespective of their depression status. Among high-quality trials of depressed CHD patients, only CBT showed significant, though small, effects. The systematic review of Van Dixoorn [85] on the effectiveness of relaxation therapy showed positive effects on cardiologic variables, anxiety and depression, and work reintegration A recent review of psychotherapy interventions for patients with ischemic heart disease [86] showed positive effects on conditions of psychological distress, on the management of traditional risk factors and with respect to some cardiovascular prognostic indices. Data from the literature on the effectiveness of the above-mentioned psychological interventions and evidence-based psychotherapy are mainly based on CBT interventions; however, one can also find evidence of efficacy of interventions based on other theoretical models, though these require further confirmatory studies. Most of the studies with CBT involve individual and/or group interventions carried out in the context of research, mainly in outpatient settings - the average duration is about one year with weekly sessions in the early stages followed by monthly sessions in the second part.

Table 3 reports the major studies on CBT interventions carried out in CHD patients [87-105].

In the literature there are few reports of psychotherapeutic interventions with a non-cognitive-behavioral orientation. A randomized clinical trial conducted in 2013 by Roncella et al. [106] shows the efficacy of a psychoanalysis intervention (group and individual) on cardiac symptoms, quality of life, and psychological/medical outcomes at 1-year follow-up. Lesperance [107] shows the effectiveness of interpersonal psychotherapy on reducing depression in a sample of patients with CHD. However, further studies are required due to the low number of studies and short follow-up duration (1 year).

The updated Cochrane Review [7] found that for people with CHD there was no evidence that psychological treatments had an effect on total mortality, risk of revascularisation procedures, or on the rate of non-fatal AMI, although the rate of cardiac mortality was reduced and there was a reduction in psychological symptoms (depression, anxiety, or stress); however, the GRADE assessments suggest considerable uncertainty surrounding these effects. There is also considerable uncertainty about who would benefit most from treatment (i.e., people with or without psychological disorders at baseline) and what the specific components of successful interventions are. For depression, psychological interventions combined with adjunct pharmacology (where deemed appropriate) for an underlying psychological disorder appeared to be more effective than interventions alone without adjunct pharmacology. For anxiety, interventions recruiting participants with an underlying psychological disorder appeared more effective than those delivered to unselected populations.

In the Panel's opinion, from the literature analysis, it can be stated that there is:

- existence of strong evidence for the efficacy of cognitive-behavioral interventions on the following variables:

- depression

- anxiety

- stress
- existence of moderate evidence for the efficacy of cognitivebehavioral interventions on cardiac outcomes

- existence of mild evidence for the efficacy:

- of interpersonal psychotherapy on depression

- of short-term psychoanalytic therapy on quality of life and cardiac outcomes

- of mindfulness interventions on anxiety, depression, stress, cardiac outcomes

\section{Cardiac surgery}

Takagi et al. [108] performed a systematic review and meta-analysis to determine whether perioperative depression and anxiety were associated with increased postoperative mortality in patients undergoing cardiac surgery. Neurocognitive and psychiatric complications are common following cardiac surgery and impact on the patient's quality of life, recovery, participation in rehabilitation and long-term mortality. Postoperative cognitive decline, depressive disorders, post-traumatic stress disorder and neurocognitive impairment related to silent brain infarcts have all been linked to the perioperative period of cardiac surgery, and can have potentially serious consequences. The accurate assessment of these conditions, particularly in determining the etiology, and impact on patients is difficult due to the poorly recognised nature of these complications as well as similarities in presentation to postoperative delirium [109].

\section{MODERATE EVIDENCE}

\section{- Anxiety and depression}

The literature search by Takagi et al. [108] included data on 236,595 patients undergoing cardiac surgery - coronary artery by-pass grafting (CABG), CABG with concomitant valve replacement, valve surgery - and showed that perioperative depression and anxiety may be associated with increased postoperative mortality. Depression and/or anxiety before an invasive intervention may negatively influence coping and recovery after the intervention.

\section{- Post-traumatic stress disorder (PTSD)}

In a narrative review, Singh [110] affirmed that PTSD has a strong association with $\mathrm{CABG}$ and can be a source of considerable morbidity and mortality, although the studies on which these statements are based are not recent. In primis, the study of Stoll et al. [111] compared patients undergoing cardiac surgery with healthy persons and those undergoing other types of surgery and noted a higher incidence of PTSD in cardiac surgery patients. The authors observed that patients after CABG with comorbid PTSD had a lower compliance with respect to use of medication, which carries the risk of an unfavorable course of the somatic disease. Also, the risk for rehospitalization after AMI is higher in patients with comorbid PTSD symptoms than in patients without.

\section{- Post-surgery neuropsychological disorders}

A systematic review of 2014 [112] stated that persistent cognitive impairment attributable to cardiovascular surgery in patients aged over 65 years is infrequent, and may reflect pre-existing cognitive impairment. In particular, CABG interventions seem to have modest effects in the medium and long term. Results cannot be generalized to the oldest-old, to women or to patients with pre-existing cognitive impairments. Postoperative decline appears to be associated with the presence of new ischemic lesions from emboli during surgery, but the pathogenesis seems still unclear and also hard to predict [113]. 
Table 3. Major studies on CBT interventions in CHD patients.

\begin{tabular}{|c|c|c|c|c|c|c|c|c|}
\hline Study & Design & Setting & Diagnosis & Patients & $\begin{array}{l}\text { Mean age } \\
\text { (years) }\end{array}$ & $\begin{array}{l}\text { Follow-up } \\
\text { (years) }\end{array}$ & Intervention & Outcomes \\
\hline $\begin{array}{l}\text { ENRICHD } \\
\text { (Berkman et al., } \\
\text { 2003) }\end{array}$ & RCT & Multi-center & AMI & $\begin{array}{l}2481 \text { ( } 1397 \text { males } \\
\text { and } 1084 \text { females; } \\
1238 \text { intervention } \\
\text { and } 1243 \\
\text { controls) }\end{array}$ & 61 & 29 months & $\begin{array}{l}\text { Group and individual } \\
\text { cognitive-behavioral } \\
\text { therapy, education, } \\
\text { relaxation, and type A } \\
\text { behavior modification } \\
\text { for } 18 \text { contact hours. }\end{array}$ & $\begin{array}{l}\text { Improvements in depression } \\
\text { and social support. There was } \\
\text { no benefit in terms of cardiac } \\
\text { outcomes or mortality after } \\
\text { follow-up. }\end{array}$ \\
\hline $\begin{array}{l}\text { Blumenthal et al., } \\
2005\end{array}$ & RCT & Single-center & $\begin{array}{l}\text { Patients with } \\
\text { stable ischemic } \\
\text { heart disease (IHD) } \\
\text { and exercise- } \\
\text { induced myocardial } \\
\text { ischemia }\end{array}$ & $\begin{array}{l}134 \text { patients } \\
\text { (92 males and } \\
42 \text { females; } 44 \\
\text { intervention and } \\
42 \text { controls } 1 \text { and } \\
48 \text { controls 2) }\end{array}$ & 63 & & $\begin{array}{l}\text { Weekly 1.5-hour } \\
\text { stress management } \\
\text { training for } 16 \text { weeks. }\end{array}$ & $\begin{array}{l}\text { Less emotional distress } \\
\text { and lower levels of depression } \\
\text { compared with usual care } \\
\text { controls. Improved markers } \\
\text { of cardiovascular risk more than } \\
\text { usual medical care alone. }\end{array}$ \\
\hline $\begin{array}{l}\text { Claesson et al. } \\
\text { (2005) }\end{array}$ & RCT & Single-center & $\begin{array}{l}\text { Ischemic heart } \\
\text { disease }\end{array}$ & $\begin{array}{l}198 \text { (only } \\
\text { females; } \\
101 \text { intervention } \\
\text { and controls) }\end{array}$ & 61 & 1 & $\begin{array}{l}\text { Cognitive-behavioral } \\
\text { stress management } \\
\text { program us usual } \\
\text { care 1-year. }\end{array}$ & $\begin{array}{l}\text { Both groups improved in all } \\
\text { psychosocial variables the rate } \\
\text { of improvement was significantly } \\
\text { greater in the intervention group } \\
\text { for self-rated stress behavior } \\
(\mathrm{P}=0.006) \text { and vital exhaustion } \\
(\mathrm{P}=0.03) \text {. }\end{array}$ \\
\hline $\begin{array}{l}\text { McLaughlin et al. } \\
\text { (2005) }\end{array}$ & RCT & Single-center & ACS & $\begin{array}{l}100 \text { (74 males } \\
\text { and } 26 \text { females; } \\
53 \text { intervention } \\
\text { and } 47 \text { controls) }\end{array}$ & 60 & & $\begin{array}{l}\text { CBT, counselling, } \\
\text { education for 8-week } \\
\text { treatment sessions } \\
\text { were } 30 \text { minutes } \\
\text { and conducted } \\
\text { by doctoral-level } \\
\text { clinicians with } \\
\text { telephone. }\end{array}$ & $\begin{array}{l}27 \% \text { improvement in depression } \\
\text { symptoms }(\mathrm{P}=0.05), 27 \% \text { in } \\
\text { anxiety }(\mathrm{P}=0.02) \text {, and a } 38 \% \\
\text { improvement in home limitations } \\
(\mathrm{P}=0.04) \text {. }\end{array}$ \\
\hline $\begin{array}{l}\text { Michalsen et al. } \\
(2005)\end{array}$ & RCT & Single-center & $\begin{array}{l}\text { Stable or } \\
\text { unstable CAD }\end{array}$ & $\begin{array}{l}101 \text { ( } 78 \text { males } \\
\text { and } 23 \text { females; } \\
48 \text { intervention } \\
\text { and } 53 \text { controls) }\end{array}$ & 59 & & $\begin{array}{l}\text { CBT, relaxation, } \\
\text { and type A behavior } \\
\text { modification } \\
\text { for } 96 \text { contact hours. }\end{array}$ & $\begin{array}{l}\text { Both groups improved in QoL, } \\
\text { and significantly greater } \\
\text { improvements for the lifestyle } \\
\text { group were found for physical } \\
\text { function and physical sum score } \\
(\mathrm{P}=0.046 \text { and } \mathrm{P}=0.045) \text {. Depression, } \\
\text { anxiety, anger and perceived stress } \\
\text { were reduced similarly in both } \\
\text { groups. Greater benefits among } \\
\text { women in the lifestyle intervention } \\
\text { us advice group for depression } \\
\text { and anger }(\mathrm{P}=0.025 \text { and } \mathrm{P}=0.040) \text {, } \\
\text { but no effects for men. }\end{array}$ \\
\hline $\begin{array}{l}\text { Sebregts et al. } \\
(2005)\end{array}$ & RCT & Single-center & AMI or CABG & $\begin{array}{l}204 \text { ( } 169 \text { males } \\
\text { and } 35 \text { females; } \\
106 \text { intervention } \\
\text { and } 98 \text { controls) }\end{array}$ & 55 & & $\begin{array}{l}\text { A combined stress } \\
\text { management } \\
\text { and health education } \\
\text { program during eight } \\
\text { weekly 2.5-h } \\
\text { sessions. }\end{array}$ & $\begin{array}{l}\text { Reduction of hostility and total } \\
\text { Type A behavior at post } \\
\text { intervention ( } \mathrm{P}=0.01) \text { and at } \\
\text { 9-month. Follow-up ( } \mathrm{P}=0.03 \text { ). } \\
\text { The intervention had no overall } \\
\text { impact on vital exhaustion and } \\
\text { depression, whereas we } \\
\text { unexpectedly found that the } \\
\text { percentage of patients with } \\
\text { major depression was reduced } \\
\text { in the control group but not } \\
\text { in the intervention group. }\end{array}$ \\
\hline $\begin{array}{l}\text { Edelman et al. } \\
(2006)\end{array}$ & RCT & Single-center & $\begin{array}{l}\text { Patients with } \\
1 \text { or more known } \\
\text { cardiovascular } \\
\text { risk factors }\end{array}$ & $\begin{array}{l}154 \text { ( } 30 \text { males } \\
\text { and } 124 \text { females; } \\
77 \text { intervention } \\
\text { and } 77 \text { controls) }\end{array}$ & 53 & 10 & $\begin{array}{l}\text { Personalized health } \\
\text { planning (PHP): } \\
\text { usual care associated } \\
\text { with educational } \\
\text { couselling and } \\
\text { mindfulness } \\
\text { meditation, } \\
\text { relaxation training, } \\
\text { stress management, } \\
\text { motivational } \\
\text { techniques, and } \\
\text { health education } \\
\text { and coaching. }\end{array}$ & $\begin{array}{l}\text { Baseline } 10 \text {-year risk of CHD was } \\
11.1 \% \text { for subjects randomized } \\
\text { to Usual Care (n=77), and } 9.3 \% \\
\text { for subjects randomized to PHP } \\
\text { (n=77). Over } 10 \text { months of the } \\
\text { intervention, CHD risk decreased } \\
\text { to } 9.8 \% \text { for UC subjects and } 7.8 \% \\
\text { for intervention subjects. } \\
\text { A multidimensional intervention } \\
\text { based on integrative medicine } \\
\text { principles reduced risk of CHD, } \\
\text { possibly by increasing exercise } \\
\text { and improving weight loss. }\end{array}$ \\
\hline
\end{tabular}


Table 3. Continued from previous page.

\begin{tabular}{|c|c|c|c|c|}
\hline Study & Design & Setting & Diagnosis & Patients \\
\hline $\begin{array}{l}\text { Koertge et al. } \\
(2008)\end{array}$ & $\mathrm{RCT}$ & Single-center & AMI, PCI or CABG & $\begin{array}{l}247 \text { (only females } \\
119 \text { intervention } \\
\text { and } 128 \text { controls) }\end{array}$ \\
\hline
\end{tabular}

$\begin{aligned} & \text { Mean age } \\ & \text { (years) }\end{aligned}$
$\begin{aligned} & \text { Follow-up } \\ & \text { (years) }\end{aligned}$
62

\section{Intervention $\quad$ Outcomes}

Group cognitive- $\quad$ For VITAL exhaustion, intention behavioral therapy, to treat analysis showed effects education, relaxation, for time $(\mathrm{P}<0.001)$ and time $\mathrm{x}$ and type A behavior treatment interaction $(\mathrm{P}=0.005)$, modification for 40 reflecting that both groups contact hours. improved over time, and that the decrease of $\mathrm{VE}$ was more pronounced in the intervention group.

\begin{tabular}{lllll}
\hline $\begin{array}{l}\text { Albus et al. } \\
(2009)\end{array}$ & RCT & Single-center & $\begin{array}{l}\text { Patients with } \\
\text { stable CHD }\end{array}$ & $\begin{array}{l}77(67 \text { males } \\
\text { and } 10 \text { females; } \\
39 \text { intervention } \\
\text { and } 38 \text { controls })\end{array}$
\end{tabular}

Multimodal, behavioral Improvement of miocardial intervention and perfusion. relaxation training 10 sessions once a week followed by 9 subsequent sessions once a month, which included group discussions, relaxation and exercise training, which continued for a period of up to 1 year.

\begin{tabular}{|c|c|c|c|c|c|c|c|c|}
\hline $\begin{array}{l}\text { Blom et al. } \\
(2009)\end{array}$ & RCT & Single-center & CAD & $\begin{array}{l}247 \text { (only females; } \\
13 \text { intervention } \\
\text { and } 122 \text { controls) }\end{array}$ & $\geq 75$ & $\begin{array}{l}\text { After } 1 \\
\text { and } 2 \text { years }\end{array}$ & $\begin{array}{l}20 \text { (2-h group } \\
\text { sessions) of stress } \\
\text { management therapy. }\end{array}$ & $\begin{array}{l}\text { Reduction of self-rated daily } \\
\text { stress behavior over time } \\
\text { compared to controls. }\end{array}$ \\
\hline $\begin{array}{l}\text { Griffiths et al. } \\
\text { (2009) }\end{array}$ & Pilot study & Single-center & $\begin{array}{l}\text { Diagnosed } \\
\text { cardiac } \\
\text { condition that } \\
\text { required cardiac } \\
\text { rehabilitation }\end{array}$ & $\begin{array}{l}6 \text { ( } 5 \text { males } \\
\text { and } 1 \text { female) }\end{array}$ & 50 & & $\begin{array}{l}\text { Mindfulness based } \\
\text { Cognitive Therapy } \\
\text { eight-week (two } \\
\text { hours per week). } \\
\text { Mindfulness-based } \\
\text { Cognitive Therapy } \\
\text { group developed by } \\
\text { Segal, Williams and } \\
\text { Teasdale (2002) } \\
\text { adapted for a cardiac } \\
\text { population. }\end{array}$ & $\begin{array}{l}\text { Development of awareness, } \\
\text { commitment, within group } \\
\text { experiences, relating to the } \\
\text { material and acceptance as } \\
\text { central experiential themes. } \\
\text { Absence of a control group } \\
\text { and small sample size number } \\
\text { is in accordance with IPA sample } \\
\text { sizes. Interpretive } \\
\text { phenomenological analysis (IPA) } \\
\text { of participant experiences. }\end{array}$ \\
\hline $\begin{array}{l}\text { Neves et al. } \\
(2009)\end{array}$ & RCT & $N$ & $\begin{array}{l}\text { Stable } \\
\text { or unstable CAD }\end{array}$ & $\begin{array}{l}81 \text { ( } 69 \text { males } \\
\text { and } 11 \text { females; } \\
41 \text { intervention } \\
\text { and } 40 \text { controls) }\end{array}$ & 60 & 2 & $\begin{array}{l}\text { Group relaxation } \\
\text { therapy for } 3 \text { months } \\
\text { us usual care. }\end{array}$ & $\begin{array}{l}\text { Perceived stress declined more } \\
\text { in the intervention group and } \\
\text { it had significantly lower heart } \\
\text { rate, blood pressure, and rate- } \\
\text { pressure product values after } \\
\text { the program ( } \mathrm{P}<\mathrm{r}=.0001) \text {. } \\
\text { Relaxation therapy was } \\
\text { associated with a positive effect } \\
\text { on psychological stress } \\
\text { and hemodynamic variables. } \\
\text { No difference in the follow-up. }\end{array}$ \\
\hline $\begin{array}{l}\text { Orth-Gomér et al. } \\
\text { (SWITCHD, } \\
2009 \text { ) }\end{array}$ & RCT & Multi-center & $\begin{array}{l}\text { AMI, PCI } \\
\text { or CABG }\end{array}$ & $\begin{array}{l}237 \text { (only females; } \\
112 \text { intervention } \\
\text { and } 125 \text { controls) }\end{array}$ & 62 & 7 & $\begin{array}{l}20 \text { Group cognitive- } \\
\text { behavioral therapy for } \\
12 \text { months. Educational } \\
\text { group sessions were } \\
\text { aimed at improving } \\
\text { knowledge of the } \\
\text { heart, healthier } \\
\text { lifestyle, training } \\
\text { skills, and improving } \\
\text { mastery of marital } \\
\text { stress, coping with } \\
\text { serious illness, } \\
\text { counteracting anxiety } \\
\text { and depression, } \\
\text { improving social } \\
\text { relations and social } \\
\text { support, and } \\
\text { practicing relaxation } \\
\text { techniques. }\end{array}$ & $\begin{array}{l}\text { Women in usual care } \\
\text { had a mortality rate of } 20 \% \text {, } \\
\text { whereas those in the } \\
\text { psychosocial intervention } \\
\text { had a mortality rate of } 7 \% \text {. } \\
\text { No women were lost } \\
\text { to follow-up. }\end{array}$ \\
\hline
\end{tabular}


Table 3. Continued from previous page.

\begin{tabular}{|c|c|c|c|c|}
\hline Study & Design & Setting & Diagnosis & Patients \\
\hline $\begin{array}{l}\text { Blumenthal et al. } \\
(2010) \\
\text { ENHANCED }\end{array}$ & RCT & Multi-center & CHD & 150 \\
\hline
\end{tabular}

$\begin{array}{lll}\begin{array}{l}\text { lean agie } \\ \text { years) }\end{array} & \begin{array}{c}\text { Follow-ulp } \\ \text { (years) }\end{array} & \text { Intervention } \\ & & \text { Stress management } \\ & \text { training (SMT) } & \text { os traditional } \\ & \text { exercise based } & \text { cardiac rehabilitation } \\ & \text { for } 12 \text { weeks. }\end{array}$

Outcomes

\begin{tabular}{|c|c|c|c|}
\hline $\begin{array}{l}\text { Gulliksson et al. RCT } \\
\text { (SUPRIM, 2011) }\end{array}$ & Single-center & $\begin{array}{l}\text { Stable or } \\
\text { unstable CAD }\end{array}$ & $\begin{array}{l}362 \text { (277 males } \\
\text { and } 85 \text { females; } \\
192 \text { intervention } \\
\text { and } 170 \text { controls) }\end{array}$ \\
\hline
\end{tabular}

\begin{tabular}{|c|c|c|c|c|}
\hline $\begin{array}{l}\text { Goodwin et al. } \\
\text { (2012) }\end{array}$ & Pilot study & Single-center & $\begin{array}{l}\text { Acute coronary } \\
\text { syndrome }\end{array}$ & $\begin{array}{l}16 \text { (5 males } \\
\text { and } 11 \text { females; } \\
\text { all intervention) }\end{array}$ \\
\hline
\end{tabular}

\begin{tabular}{|c|c|c|c|c|c|c|}
\hline $\begin{array}{l}\text { Orth Gomer et al. } \\
\text { (2012) }\end{array}$ & $\begin{array}{l}\text { Observational } \\
\text { study }\end{array}$ & Single-center & $\begin{array}{l}\text { Acute coronary } \\
\text { syndrome } \\
\text { AMI, PTCI } \\
\text { or CABG }\end{array}$ & $\begin{array}{l}30 \text { (19 males } \\
\text { and } 11 \text { females; } \\
\text { all intervention) }\end{array}$ & 55.5 & 9 \\
\hline
\end{tabular}

CBT 40 contact hours
spanning 1 year 20
two-hour sessions

stress management.

The groups consisted

of 5 to 9 same-sex

participants, 5 key

elements (education, CBT

self-monitoring, skills of recurrent CVD and AMI.

training, cognitive

restructuring, and

spiritual development)

and was focused

on stress reduction

and management.

\section{ACT four, 90-min Satisfaction with the}

group sessions

focused on developing

mindfulness and

distress tolerance

skills, and

strengthening

commitment to

health-related

behavior change.

CBT: ten sessions No gender differences but of two hours of discussion styles varied between stress management the women and men, Women were program. intervention. Large

and moderate increases

in physical activity from

pre- to post-treatment. more open and more personal.

Family issues were more frequent than job issues, although all women were employed outside their homes. Men talked about concrete and practical things, mostly about their jobs, and not directly about their feelings. Daily stresses of life decreased significantly for both men and women, but more so for women. Depressive thoughts were low at baseline, and there was no change over time. In contrast, anxiety scores were high at baseline and decreased significantly, but more so for women than for men.

\begin{tabular}{|c|c|c|c|c|c|c|c|c|}
\hline $\begin{array}{l}\text { Murphy et al. } \\
\text { (2013) }\end{array}$ & RCT & Multi-center & $\begin{array}{l}\text { AMI, PTCI } \\
\text { or CABG }\end{array}$ & $\begin{array}{l}275 \text { (238 males } \\
\text { and } 37 \text { females; } \\
139 \text { intervention } \\
\text { and } 136 \\
\text { controls) }\end{array}$ & 59 & 2 & $\begin{array}{l}\text { "Beating Heart } \\
\text { Problems" cognitive- } \\
\text { behavioral therapy } \\
\text { and motivational } \\
\text { interviewing program } \\
\text { us usual care. }\end{array}$ & $\begin{array}{l}\text { Compared with the Cgroup patients, } \\
\text { intervention group patients tended } \\
\text { toward greater reduction in 2-year } \\
\text { risk of cardiac event, at both the } 4 \text {-and } \\
\text { 12-month follow-up. Significantbenefits } \\
\text { in dietary fat intake and functional } \\
\text { capacity were also evident. }\end{array}$ \\
\hline $\begin{array}{l}\text { Parswani et al. } \\
\text { (2013) }\end{array}$ & $\mathrm{RCT}$ & Single-center & CHD & $\begin{array}{l}30 \text { (only males; } \\
15 \text { intervention } \\
\text { and } 15 \text { controls) }\end{array}$ & 48.5 & 3 months & $\begin{array}{l}\text { Mindfulness-Based } \\
\text { Stress Reduction } \\
\text { (MBSR) program. }\end{array}$ & $\begin{array}{l}\text { Significant reduction in symptoms } \\
\text { of anxiety and depression, } \\
\text { perceived stress, blood pressure } \\
\text { and body mass index in patients } \\
\text { of the MBSR group after the } \\
\text { completion of intervention } \\
\text { assessment. At 3-month follow-up, } \\
\text { therapeutic gains were maintained } \\
\text { in patients of the MBSR group. }\end{array}$ \\
\hline
\end{tabular}


In a long-term study with a median follow-up of 11 years in patients following cardiac surgery, cognitive dysfunction present at 6 months was associated with increased long-term mortality [114], further demonstrating that the consequences of postoperative cognitive disfunction are likely to have long-term implications that are more significant than simply that of a 'transient postoperative state'. Cognitive functions were reported to be mildly or not significantly impaired after transcatheter aortic valve implantation (TAVI) [115]. Postoperative delirium is associated with increased anxiety and depression at 6 to 9 months, and future investigation should seek to evaluate the utility of screening programs for affective disorders in those individuals who develop delirium in the postoperative period [116].

In summary, in the opinion of the Panel, from the literature analysis there emerges:

- moderate evidence of an association between the following variables and clinical condition

- Anxiety and depression

- Post-traumatic stress disorder

- Post-interventions neuropsychological disorders

\section{PSYCHOLOGICAL INTERVENTIONS}

A literature concerning specific psychological interventions can not be found.

Suarez-Bagnasco [117] suggests that the study of psychological issues in these cardiac diseases is relevant and could provide information about specific needs requiring psychological interventions as well as be useful for the design of specialized care training and practice.

A good practice intervention is recommended.

\section{Chronic heart failure}

The European guidelines [118] underline that CHF is a common chronic disease with poor prognosis and significant quality of life limitations. Patients are required to follow a complex regimen of self-care behaviors including medication, self-monitoring of symptoms, diet and exercise. Mental comorbidities such as depressive and anxiety disorders are common in patients with CHF. Depressive comorbidities are present in about $20 \%$ of patients, anxiety comorbidities in up to $40 \%$ [119].

\section{STRONG EVIDENCE}

\section{- Behavioral risk factors}

Obesity, sedentary lifestyle, smoking, and cocaine and alcohol use are independent predictors of CHF [118,120-122]. Goel et al., however, show that light to moderate alcohol intake has been associated with lower risk of heart failure [25].

\section{- Depression}

A systematic review and meta-analysis suggests that depression is an important and independent predictor of all-cause mortality among CHF patients, while anxiety does not appear to have a strong effect [100].

\section{- Anxiety}

The above-mentioned systematic review and meta-analysis [100] showed that anxiety does not appear to have as strong an effect as depression in predicting all-cause mortality among CHF patients, but anxiety is negatively associated with self-care behavior. However, this effect disappears behind the stronger influence of depression on self-care. It is important to consider mental comorbidities in patients with CHF [123].

\section{MODERATE EVIDENCE}

\section{- Social factors}

Low socio-economic status (SES) as well as immigrant status are independent predictors of CHF [124,125]. Social instability and poor social support, instability and precariousness of affective/interpersonal relationships, not being married, living alone, some social and environmental factors such as immigrant status, distance from the hospital and precarious housing conditions negatively affect the outcome [124-127].

\section{- Personality factors}

Type D personality. Data in the literature are contradictory and inconclusive [61,128-132].

\section{- Positive psychological variables}

Positive psychological well-being improves the outcome in terms of quality of life and disease management [133,134].

\section{- Neuropsychological disorders}

Mild cognitive impairment (MCI) is common in HF and impacts on patients' engagement in self-care, yet it is frequently not detected.[135].

\section{- Sleep disorders}

Sleep disorders and apnea influence the outcome [136,137].

In summary, in the opinion of the Panel, from the literature analysis there emerges:

- strong evidence of an association between the following variables and disease onset/outcome:

- Behavioral risk factors, in particular alcohol and cocaine use

- Depression

- Anxiety

- moderate evidence of an association between the following variables and disease onset/outcome:

- social factors

- personality factors (type D)

- moderate evidence of an association between the following variables and outcome of the disease:

- positive psychological variables

- neuropsychological disorders

- sleep disorders

\section{PSYCHOLOGICAL INTERVENTIONS}

The analysis of the literature [138-141] shows that it is fundamental to treat patients with CHF from the perspective of a chronic and progressive disease, during which they are called upon to put into action cognitive, emotional and behavioral resources that will allow them to live with the disease, adhere to complex therapeutic regimens and maintain a reasonable level of quality of life. The changes of role in the personal, family, and social/work context involve problematic emotional states; moreover, adherence to prescriptions is often conditioned by the complex pharmacological therapy, by the need to monitor physiological parameters and symptoms, and by food restrictions (salt consumption, intake of liquids, abstention from alcohol).

From the literature and from clinical experience it emerges that interventions to optimize the CHF treatment, reduce hospitalizations and mortality, and improve quality of life and management of the disease, carried out during the stay in hospital or at home with telemedicine methods or face-to-face interventions, are linked to two key aspects: i) self-management and adherence [142-147]; ii) depression and anxiety [148-150].

Self-management should be promoted right from the outset, maintained throughout the course of the illness, and sustained in the 
phases of instability, in the transition from hospital to home and in the terminal phases [139,145,151-153]. Interventions to improve self-management do not affect the emotional structure [153]. In a recent review [154] on the effectiveness of psychological interventions on self-care, and on psychological and health outcomes in patients with CHF, the authors showed that nurses play an important role in patient education and secondary prevention. Compared to other professionals, nurses have more patient contact opportunities and are more holistic in all aspects of disease management; therefore, more nurses can be trained to incorporate the brief psychological techniques (such as motivational interviews and CBT) to maximize the intervention's effectiveness. The main limitation of the review is the moderate-to-high level of heterogeneity among the included studies, which could partially undermine the reliability and reproducibility of the results. Due to the heterogeneity of the studies, no definitive conclusions on the optimal format and forms of intervention could be drawn. Replication of the studies is required in the future to isolate the active component of the interventions and identify the ideal format and dosage of interventions.

An improvement of adherence is achieved through effective communication and by defining with the patient an interactive therapeutic plan aimed at the respect, recognition, correction and management of these aspects:

- Psychosocial: psychological problems, neuropsychological deficits and poor socio-family support [155,156].

- Cognitive behavioral: cognitive distortions about awareness, selfmanagement of the disease at home and self-efficacy [156-158].

- Communications: [159, 146].

In published reports, details on specific counseling or psychotherapeutic interventions (cognitive therapy and stress management) for patients with CHF are often lumped together as part of the group of non-pharmacological approaches (including physical activity and dietary prescriptions) or are included in the global rehabilitation treatment or as part of the multidisciplinary hospital interventions [160-167], so it is difficult to document their specific effectiveness.

Psychological interventions can be performed to address dysfunctional aspects (cognitive, emotional or behavioral) in the management of the disease, or to provide counseling to optimize coping strategies, or to provide psychological support during the stabilization phase [168].

Many reports focus on depression and the provision of emotional support or counseling in order to understand the patient's needs, manage their emotional response to the disease, improve quality of life and optimize the physical outcomes of the therapeutic interventions.

In a recent systematic review and meta-analysis [169], a CBT intervention on depression, quality of life, hospitalizations and mortality in CHF patients was associated with a greater improvement, compared to usual care, in depression scores both at the end of the CBT program and 3 months later. Greater improvement in quality of life scores was evident for the CBT group initially after CBT sessions, but there was no difference at 3 months. Hospital admissions and mortality were similar in the two treatment groups. CBT may be more effective than usual care at improving depression scores and quality of life for heart failure patients initially following CBT and for depression at 3 months. The authors suggest larger and more robust randomized controlled trials (RCTs) to evaluate the long-term clinical effects.

There are also specific interventions based on specific theoretical health models [170] or therapies associated with positive psychology [171] and with the most recent CBT therapy [172-174].

Telerehabilitation may serve as a helpful strategy for continuing at a distance the monitoring and management of a patient, allowing faceto-face interventions, including with the patient's family. To date, only a small number of studies have been dedicated to studying the psycho- logical aspects of telerehabilitation [175]. These patients could receive parallel psychological support and tele-assistance from the telemonitoring team (nurse, physician, physiotherapist). In any case, telemedicine interventions can provide benefits to heart failure patients only as part of a shared and integrated multidisciplinary and multi-professional 'chronic care model' [176].

In this context, one can envisage:

- interventions aimed at self-management based on brief psychological techniques (such as motivational interviews and CBT) performed by healthcare operators, especially nurses, trained by psychologists

- psychological/psychotherapeutic interventions carried out by psychologists/psychotherapists, of a prevelently cognitive-behavioral type

- telemedicine interventions, performed by healthcare operators, especially nurses, which should be trained by psychologists

In the Panel's opinion, from this analysis of the literature there emerges moderate evidence of efficacy

- for cognitive-behavioral interventions

- for psychoeducational and disease management interventions.

\section{Heart transplantation}

The specific Guidelines [177,178] affirm that the psychologist should routinely assess all patients being considered for heart transplantation (HT), before wait-listing for transplantation. Evaluation should include an assessment of the patient's ability to give informed consent and comply with instructions, including drug therapy, as well as assessment of the support systems in place at home or in the community. This assessment focuses on the following: i) social support and the ability of the social support network to cope with the stressors of HT care; ii) patient understanding of the requirements, risks and benefits of HT; iii) adherence to the medical care plan; iv) psychopathology; v) cognitive assessment. The literature on psychological comorbidity $[177,179,180]$ shows a high incidence of anxiety-depressive disorders (30\%) pre-transplantation, which tends to decrease in post-transplantation. Psychological/psychiatric contraindications are first reviewed by the psychologist and, where necessary, a psychiatrist is consulted for further assessment and/or a second opinion.

\section{STRONG EVIDENCE}

\section{- Behavioral risk factors}

The presence of substance-related disorders, personality disorders or a history of medication non adherence are powerful predictors of failure to comply with the medical regimen and, therefore, are associated with increased morbidity and mortality in HT patients [180-182].

\section{- Depression}

Major depression pre-transplant is a negative prognostic factor especially if associated with poor social support [183,184]. It adversely affects adherence to exercise and participation in daily life activities [185].

Its incidence was $7.9 \%$ for severe or moderate depression [186] and $33-69 \%$ for the less severe levels [187,188]. If the depressive symptomatology is treated pharmacologically, symptoms can be reduced and the health status improved post-transplant [189]. A recent systematic review indicated that depression increases the risk of post-transplant mortality [190]. The presence of depression post-transplantation is frequent [191], equal to $41 \%$. Grandi et al. [192] reported that demoralization in combination with depres- 
sion predicted more acute rejection episodes in the 6 -year period post-transplant than either variable considered independently. Major depression prior to heart transplantation is a risk factor for post-transplant malignancies and PTSD symptoms are a predictor of post-transplant poor adherence [191].

\section{MODERATE EVIDENCE}

\section{- Social factors}

The presence of poor social support post-transplantation is correlated to a worse quality of life [193] as is low socio-economic status, living in an urban reality [182] and having a caregiver with anxiousdepressive symptoms [194,195]. Conversely, high education level and a medium-high economic status are predictive of greater survival $[182,196,197]$. Any patient for whom social supports are judged to be insufficient to ensure care compliance in the outpatient setting may be regarded as having a relative contraindication to HT [178].

\section{- Anxiety}

In the recent systematic review cited above, anxiety was not associated with e risk of post-transplant mortality and morbidity [190]. However, anxiety appears to be present in the pre-transplant waiting-list phase $[179,180,198]$. Anxiety negatively affects the psychophysical health status [199].

\section{- Stress}

HT is a very stressful experience for heart transplant candidates, and recipients and patients have to cope with significant medical and emotional challenges related to the workup they must undergo for listing, waiting for a donor heart to become available, undergoing surgery and post-operative recovery, and adjustment to life with a transplanted organ [180].

At 5 and 10 years after HT, the most bothersome stressors regard work, school, and financial issues. Patients at 10 years after transplant reported less stress, similar stress intensity, and less use and perceived effectiveness of negative coping than patients at 5 years after transplant. In the long-term after transplant, demographic characteristics, psychologic problems, negative coping, and clinical factors were related to stress frequency and/or intensity [200]. HT-related stress occurs in the long-term after surgery. Types of transplant-related stress and factors related to stress confirm the importance of ongoing psychologic and clinical support after HT [200].

\section{- Post-traumatic stress disorder}

Its incidence in transplanted patients is $12 \%$. In a study [191], the estimated frequency of psychiatric diagnoses after HT was $12 \%$ for transplantation-related PTSD and 41\% for major depression. The presence of an episode of major depression prior to HT is a significant independent risk factor for post-transplant malignancies. Age, post-transplant malignancies and poor adherence are significant predictors of mortality in the survival analyses. Mortality was significantly higher in patients with HT-related PTSD comorbidity, possibly as a result of the lower compliance in these patients or the fact that PTSD itself is predictive for poor health status.

\section{- Personality factors}

Neuroticism $[179,180]$ is correlated to anxiety and depression, thus constituting a predictive factor of psychopathology 12 months after HT. High levels of hostility are an independent predictor of subsequent mortality. Part of post-transplant nonadherence seems also to be determined by personality. Personality traits refer to a dimensional taxonomy created to understand normal personality functioning, and do not necessarily reflect psychopathology. Patients with low conscientiousness may be criticized for their carelessness, negligence, and failure to stay within the lines, while patients with high conscientiousness are disciplined, organized, goal-oriented, and have a high need for structure, i.e. all characteristics that may help people in treatment adherence [181].

\section{- Personality factors}

Type D is a predictor of morbidity and mortality [201,202].

\section{- Disease management}

Different studies have found that HT candidates use positive coping strategies more frequently than maladaptative coping strategies such as denial, avoidance or disengagement [197,203]. Consistent with the results obtained by the group of Burker [197,203], maladaptive coping styles (including disengagement dimension and some help-seeking traits such as venting of emotions or seeking emotional support) were associated with the presence of psychiatric symptoms in a group of patients [179], also after a follow-up of 12 months [180]. Adherence was poor post-transplantation [204,205]. Prognostically favorable factors for adherence were high education level and having a female caregiver or being a female [205].

- Positive psychological variables

The state of psychophysical wellbeing, optimism and the perception of exercising active control over the disease are prognostically favorable indicators for the outcome [206,207].

\section{- Neuropsychological disorders}

They have an incidence in the pre-transplant phase that ranges from 15 to $59 \%$ [187], while other studies show an incidence equal to $86 \%$ in particular in the executive functions [208]. There are no indications for excluding from the list for HT patients with mental retardation and specific cognitive deficits [187,208,209]. A substantial proportion of long-term survivors of HT might be cognitively impaired. The level of impairment appears comparable to what is defined in the literature as mild cognitive impairment [210]. The benefit of HT in patients with severe cognitive-behavioral disabilities or dementia (e.g. self-injurious behavior, inability to understand and cooperate with medical care) has not been established; on the contrary, it has the potential for harm and, therefore, HT cannot be recommended for this subgroup of patients [178].

In summary, in the opinion of the Panel, from the literature analysis there emerges:

- strong evidence of an association between the following variables and the conditions of pre- and post-transplant:

- Behavioral risk factors

- Depression

- moderate evidence of an association between the following variables and the conditions of pre- and post-transplant:

- Social factors

- Anxiety

- Stress

- Post-traumatic stress disorder

- Personality factors

- Disease management

- Positive psychological variables

- Neuropsychological disorders

\section{PSYCHOLOGICAL INTERVENTIONS}

\section{Psychotherapeutic interventions}

A recent systematic review recommends, as good practice, psychotherapeutic interventions of a cognitive-behavioral type, stress management strategies and relaxation techniques as a means to reduce the state of psychological distress and promote improved quality of life. In post-transplantation, also psycho-social support interventions carried out telematically via the Internet have shown to be effective [211]. The use of mindfulness training (mindfulness-based stress re- 
duction, MSBR) lasting 8 weeks was effective in reducing symptoms of anxiety, depressive symptoms and sleep disorders post-transplant [212]. Observational studies recommend the practice of individual psychotherapeutic interventions aimed not only at the patient but also at the caregiver and the healthcare team [213].

\section{Management interventions}

The patient's adherence to treatment, psychophysical wellbeing and quality of life are better if the healthcare team has developed adequate interpersonal relationship skills and uses strategies of motivational counseling [214]. Management models that include educational interventions, periodic monitoring and telematic support extended to caregivers in the months following the transplant event are predictive of good adherence to treatment [215,216]. It is also recommended to provide interventions for the prevention of relapse in smoker patients [217].

In summary, in the opinion of the Panel, from the literature analysis there emerges:

- Strong evidence for the efficacy of cognitive-behavioral interventions in reducing the state of psychological distress

- Moderate evidence for the efficacy of psychoeducational and management interventions

\section{Mechanical ventricular assist devices}

Currently there are not many studies that have investigated the psychological aspects, and the number of patients examined is very modest. Two systematic reviews investigated the impact of left ventricular assist device (LVAD) implantation on psychological variables [218,219], and showed an improvement in the state of psychophysical health, depression and anxiety scores in patients after LVAD implantation. Factors contributing to changes in depression and anxiety after the LVAD implant could be related to the improvement in acute heart failure symptoms, functional capacity, and quality of life [220].

\section{MODERATE EVIDENCE}

\section{- Acute and chronic stress}

The immediate post-operative period is associated with an increase in negative emotions (fear of the outcome of the interventions and of hospitalization) [221].

- Depression

Depression is particularly present in the post-implantation period [222-226].

- Anxiety Anxiety is frequent in patients with LVAD [222-226]

- Psycho-physiological sleep disorders

After LVAD implantation there are problems in the area of sleep that correlate with the presence of anxiety and depression [219,227,228].

\section{- Neuropsychological disorders}

In patients with LVAD implantation, cognitive dysfunctions may be present, but they are mainly found in older patients and in those with LVAD as destination therapy [229]. In general, the LVAD implant seems to arrest the cognitive decline [230] and, in the space of 24 months, there is an improvement in cognitive functions with respect to patients with advanced heart failure [231-233].

In summary, in the opinion of the Panel, from the literature analysis there emerges moderate evidence for an association between implanted LVAD and the following variables:
- Depression

- Anxiety

- Acute and chronic stress

- Psycho-physiological sleep disorders

- Cognitive deficits

\section{PSYCHOLOGICAL INTERVENTIONS}

To date, there are no RCTs on large populations able to demonstrate the efficacy of a specific psychological intervention on patients with LVAD. There are indications that patients who undergo, post-LVAD implantation, a course of treatment including psycho-education, re-education in physical activity and self-care, as well as psychological support to the patient and caregiver, show greater functional improvement in depression [234-239], in maintenance of a correct diet and in maintenance of adequate physical activity [240].

In the opinion of the Panel, from the analysis of the literature there emerges:

- $\quad$ mild evidence for the efficacy of cognitive-behavioral interventions in reducing the state of psychological distress

- mild evidence for the efficacy of psychoeducational and management interventions

\section{Implantable cardioverter-defibrillator (ICD)}

The acceptance of the ICD appears to be influenced by a number of variables such as psychological morbidity, advanced age, severity of the disease, onset of anxious or depressive symptoms, type D personality, worry about the ICD implantation, and understanding of the benefits and disadvantages of the ICD, which would seem to impact on the perceived quality of life [241-244].

\section{MODERATE EVIDENCE}

\section{- Depression}

The frequency and severity of depressive symptoms would appear to increase in relation to the severity of the underlying $\mathrm{CHF}$ [245,246].

\section{- Anxiety and fear}

Catastrophic thoughts underlying the manifestation of anxiety provoke in the patient the avoidance of daily, physical and sexual activities $[242,247]$ or the presence of anticipatory anxiety in relation to random stimuli such as, for example, increased heart rate during moderate physical activity [248]. In particular, higher levels of anxiety emerged in young patients [249] and in women especially as regards body image $[250,251]$. The results of the PainFree SST Clinical Trial [252] showed that ICD shocks have a longlasting, adverse impact on both objective, device-measured physical activity and subjective patient-reported outcomes of quality of life and shock anxiety. Shock anxiety increased in shocked patients and remained significantly elevated at 24 months, regardless of whether the shock delivery was appropriate or inappropriate. Successful management of ICD patients requires attention to clinically relevant behavioral and psychological outcomes to speed their recovery and return to activities of daily living.

- Post-traumatic stress disorder

In a narrative review, Sears [253] found that patients under the age of 50 years, female, with psychiatric pre-morbidity, poor social support and less than 5 discharges (appropriate or inappropriate) were at higher risk of PTSD. Furthermore, the presence of PTSD 
appears to be associated with a greater percentage of shock experiences and mortality at 5 years after implantation compared to patients who did not develop PTSD [253].

- Type D personality

Patients with type D personality are more likely to develop depression or anxiety disorder pre-implant because they are more exposed to psychological distress, morbidity and mortality [254,255]. Patients with a younger age, increased depression score at baseline, and Type D personality were especially prone to experience PTSD and anxiety symptomatology at 12 months follow-up [244].

\section{- Positive psychological variables}

In the WEBCARE study [256], optimism was found to be associated with less distress, and possibly it helps safeguard mental health in ICD patients. Increasing optimism might be the way forward to reduce long-term distress and impaired health status.

- Neuropsychological disorders

These deficits are more present in ICD patients who have experienced appropriate shocks. Difficulties emerged in the ability to concentrate, visual attention capacity and short-term memory independently of age and cultural level. Patients with pre-implant cognitive deficits have a lower probability of survival [257,258].

In summary, in the opinion of the Panel, from the literature analysis there emerges moderate evidence of an association between ICD wearers and the following variables:

- Depression

- Anxiety

- Post-traumatic stress disorder

- Type D personality

- Cognitive deficits

\section{PSYCHOLOGICAL INTERVENTIONS}

The detection of elements of psychological involvement and daily clinical practice both make it clear that there is a pressing need for psychological treatments for these patients. The literature indicates the effectiveness of:

- Psycho-educational interventions:

Evidence from the literature shows that there is a substantial consensus among different researchers on the importance of intervening at a first level with education on the nature, modes and goals of action of the device $[242,259]$

- Individual psychotherapy, in particular CBT:

This is identified as elective treatment and as having a greater degree of efficacy in the treatment of psychopathological symptoms related to the ICD device [260-262]

- Psychotherapy based on mindfulness:

It can increase self-monitoring capacities, metacognitive skills and body awareness [263]

- Techniques of muscle relaxation and yoga (if associated with CBT): [264]

- Support groups and psychological support interventions: These are effective in reducing anxiety-depressive symptoms [265], in reinforcing coping strategies and in appropriately recognizing physical signals [266].

- Web-based behavioral intervention:

In a clinical trial of a Web-based behavioral intervention for ICD patients, the Web-based treatment was not superior to usual care on the long-term regarding patient reported outcomes. Future studies are warranted to examine the applicability of blended-care models and focus on further personalizing the program in order to increase adherence and improve outcomes. [267].
In the Panel's opinion, from the literature analysis there emerges: - strong evidence for the efficacy of psychotherapeutic interventions, prevalently cognitive-behavioral, integrated with techniques of mindfulness and relaxation

- moderate evidence for the efficacy of psycho-educational interventions, support group interventions and psychological support interventions

\section{Pulmonary hypertension}

Living with a serious illness such as pulmonary hypertension can be a continuous challenge and requires cognitive, emotional and behavioral adaptation $[268,269]$. The uncertainty of the disease and the resulting disability can have a profound impact on quality of life [270], in particular on relationships with others, on cognitive abilities, emotions and on spirituality. The experience of the disease leads to a reformulation of the self, that the person is not always aware of. Anxiety, depression, panic attacks [268, 271-273] and sleep disorders [274] are the most common disturbances. In these patients, often of a young age, there is also an overlap with issues related to pregnancy.

The analysis of the scant literature available to date permits only to presume moderate evidence for the association between the following variables and clinical condition:

- Depression

- Anxiety/panic

- Psychophysiological sleep disorders

\section{PSYCHOLOGICAL INTERVENTIONS}

These include the treatment of anxiety, depression, and panic attacks, where needed. Verma et al. [273] suggest a combination of pharmacotherapy and psychotherapy, in particular CBT. There exist few studies on psychological interventions in pulmonary hypertension [275-277]. In particular, attention is focused on the teaching of relaxation and slow breathing techniques [275,277].

ECS/ERS guidelines [278] affirm that psychosocial support should be offered to patients with PAH (level I-C recommendation).

The Panel retains that at present there is no clear evidence of the efficacy of specific psychological interventions.

\section{Grown-up congenital heart (GUCH)}

There is no specific literature on CPR in GUCH patients. Recent reports $[279,280]$ indicate the need for psychosocial support and for the inclusion of adult congenital cardiac patients in traditional cardiologic rehabilitation programs, and most studies indicate that there is no relation between diagnosis, physical function or presence of residual symptoms and worse psychological functioning [281-283].

\section{MODERATE EVIDENCE}

\section{- Social factors}

Loneliness and absence of social support [281,284], and perceived economic difficulty [284] are associated to a larger extent with symptoms of anxiety and depression than the health condition itself.

\section{- Depression and anxiety}

Most studies indicate the absence of a relationship between diagnosis, physical function or presence of residual symptoms and anxiety/depression [281,284-287]; nevertheless GUCH patients wearing an ICD show higher levels of anxiety [288] and in some studies 
using psychiatric interviews previously undetected disorders of anxiety and depression emerged [285,287]. Furthermore, in heart disease patients with a high level of anxiety - but only in these patients - a greater vulnerability has been found for an exaggerated perception of cardiac symptoms [289].

- Knowledge, representation, and awareness of the disease The conceptualization and the severity of the disease are difficult to understand on account of the multifactorial nature of the disease [290]. Patients generally present a good awareness of treatment and of the need for follow-up. There are, however, difficulties of understanding related to: the anatomy of the heart defect, factors contributing to the onset of endocarditis, the impact of smoking and alcohol, the inheritance of a heart condition [291]. Furthermore, the perceived state of health $[281,292]$ and the imposition of limits more than the disease condition itself are related to depressive symptoms, to the psychological well-being pre-intervention and to emotional and behavioral problems.

- Disease management and positive psychological variables There are no significant differences in terms of psychological functioning between normal healthy subjects and patients with GUCH on the contrary, in some cases with GUCH there is a better functioning [282,285,293]. Possible explanations could be related to a greater sense of coherence in GUCH patients [294] or to the fact that negation and high achievement motivation could influence patients in self-report questionnaires to present an image of themselves that is socially more desirable [293].

\section{- Gender}

Women show greater emotional and behavioral problems than men in regard to the presence of a surgical scar and in relation to problems associated with pregnancy [295].

In summary, in the opinion of the Panel, from the literature analysis there emerges moderate evidence for an association between the following variables and GUCH:

- Social factors

- Depression

- Anxiety

- Knowledge, representation, awareness of the disease

\section{PSYCHOLOGICAL INTERVENTIONS}

Concerning psychological interventions in GUCH patients there are few specialized programs [296] and no published data on psychological interventions [297,298]. In a recent article analyzing the psychological needs of patients referred to a psychology service [296], the main psychological concerns were: generalized anxiety, heart condition-related anxiety, low mood tone, and difficulty in managing a medical condition. On average, patients received 8 sessions of psychotherapy which consisted of cognitive therapy, relaxation techniques and training in communication skills: $88 \%$ of the patients reported a reduction or absence of psychological distress at the end of the sessions.

The Panel believes that at present there is no clear evidence of the efficacy of specific psychological interventions.

\section{Older/oldest patients ( $\geq 75$ years)}

The extreme variability of the aging process makes the applicability of EBM in patients over 75 years of age complex. Moreover, in the clinical trials conducted so far, the number of patients in this age-group is always very modest and, moreover, their clinical features are poorly representative of the elderly people in the real world. In fact, they are patients with a single pathology and who do not show significant cog- nitive deficits or significant functional limitations. In the real world, on the other hand, more than $50 \%$ of people over 75 years are affected by a combination of three or more chronic diseases in heterogeneous patterns, the cumulative effect of which is different for each one. It is therefore essential that the approach to the elderly patient maintain always a high degree of flexibility with respect to the Guideline recommendations available [299].

In particular, in inpatients aged over 75 years undergoing cardiac rehabilitation, the rate of prevalence of frailty varies from 10 to $60 \%$ depending on the weight of the cardiovascular disease [300], and a recent update of the AHA/ACC has stressed that frailty is a crucial factor both in prognosis and in planning of the rehabilitative intervention, in that, if present, it calls for a utterly specific approach with patient-centered and carefully calibrated interventions, so as to maximize the benefits and minimize the risk of adverse events [301].

Hence, the core element indispensable for a correct approach to the cardiac patient over 75 years is the distinction between an elderly cardiac patient and a 'frail' elderly cardiac patient. There are several interpretative models of frailty but the most convincing for clinical practice is that developed by Fried [302] from which stems a working definition of frailty as an organic syndrome that reflects a condition of reduced physiological reserve and of high vulnerability to stressors [303]. The stressors can be determined by the disease condition, acute or chronic, or they can be iatrogenic, i.e. secondary to the different interventions, not only surgical and/or pharmacological but also interventions on lifestyle and on the environment [304]. A recent metaanalysis highlights how frail cardiac patients, when exposed to such stressors, are at risk of marked and often disproportionate adverse events, complications, functional decline, disability and death [305].

Frailty, closely related to comorbidity and disability, is characterized in its physical component by three or more of the following elements: muscle weakness, weight loss, slowed gait, fatigue and low levels of physical activity [302], but it can also be conditioned by problems of the psychic sphere (e.g., cognitive deficits or depressive symptoms) which can be associated to specific alterations of many physiological and biological variables, such as markers of inflammation, coagulation and metabolism.

\section{STRONG EVIDENCE}

\section{- Depression}

Depression is a consolidated independent risk factor for cardiovascular disease in the elderly population. A systematic review [306] and data obtained from the Health and Retirement Study [307] support a bidirectional association between depression and frailty which appears to be greater, though not significantly, in women.

- Cognitive deficits

Cognitive impairment, even without reaching the diagnostic criteria of dementia, is high among patients with heart disease aged over 75 years, and the results from a prospective study based on the AHA Life's Simple 7 and incident cognitive impairment [308] show an association with cardiovascular disease and more generally with an incorrect lifestyle. However, the cause-effect relationship between cardiovascular disease and cognitive impairment is very complex in the over-75 age-group, especially if the patient is frail, and therefore a highly cautious approach, as personalized as possible, is necessary for the assessment and intervention.

\section{MODERATE EVIDENCE}

\section{- Anxiety}

A prospective cohort study conducted on 148 elderly patients [309] underlined the negative prognostic role of a high preoperative level of anxiety on postoperative mortality and morbidity. Older patients 
generally tend to report less symptoms of anxiety; however, when these symptoms are present, age does not appear to act as mediator between level of anxiety and increased risk of death due to a cardiac event [304].

\section{- Stress}

A recent cohort study with control group [310] highlighted an association between death of the partner and a cardiovascular event in the immediate weeks and months following.

\section{- Social factors}

In the frail elderly patient, the data available on the protective action of psycho-social resources are still controversial: the results of the Longitudinal Aging Study Amsterdam [LASA], a population study conducted on 1665 subjects aged 55 to 85 years, highlighted an absence of significant interaction between frailty and psychosocial resources, understood as self-efficacy, emotional and instrumental support, with respect to functional decline and mortality at 3 years [311]. These findings suggest that only in the initial stages of frailty do psycho-social resources exert a protective effect, which is then lost when the functional decline is very advanced.

\section{MILD EVIDENCE}

\section{- Personality factors}

The results of a systematic review [312] are interesting regarding the association between hostility and cardiovascular risk: in patients aged over 75 years, hostility is not frequent but when it is present it appears significantly associated with greater body weight, greater anxiety and depression, a higher tendency to somatization and a lower quality of life. This pattern appears to be particularly sensitive to rehabilitation.

\section{- Health literacy}

The AHA statement on secondary prevention in elderly cardiac patients [304] emphasized the association between health literacy and clinical condition. In patients over 75 years old, especially if frail, a careful assessment of the costs and benefits of each single intervention is necessary: communication with the patient and caregiver must be as effective as possible and the information must be given in a manner appropriate to their level of health literacy. The communication style with patients aged over 75 years must also take into account that aging is usually associated with sensory impairment (sight, hearing) and cognitive deficits and also the caregiver of an elderly patient, if the spouse, may be affected by sensory impairment [313].

In summary, in the opinion of the Panel, from the literature analysis there emerges an association between the following variables and cardiac disease in patients aged over 75 years:

- strong evidence:

- Depression

- Cognitive deficits

- moderate evidence:

- Anxiety

- Stress

- Social factors

- mild evidence:

- Personality factors

- Health literacy

\section{PSYCHOLOGICAL INTERVENTIONS}

The limited literature available on patients of this age-group makes it very hard to define the specific psychological interventions carried out as part of the rehabilitation program, since the scant available evi- dence support the global efficacy of cardiac rehabilitation regarding both the various psycho-social risk factors and the cognitive sphere. The essential requirement of each intervention is a systematic approach to the patient, so as to incorporate the full complexity related to advanced age in every decision made, even if there are no signs of frailty [301]. Identifying which interventions should not be started or should be interrupted can be extremely complicated in this patient population, even for the psychologist. Factors to be considered include quantification of the benefit in terms of reduction of baseline risk compared to the outcome considered, risk of adverse events, and assessment of the expected benefits with respect to life expectancy [299].

Several studies with moderate evidence report comprehensive cardiac rehabilitation to be effective in reducing depression and of anxiety [312]. In order to understand the depression/frailty relationship, it is necessary to weigh carefully the depressive symptoms in terms of their biological or clinical (cognitive-behavioral) structure: major depression, strongly biological, is an independent risk factor; a depressive syndrome, on the contrary, could be the manifestation of difficulty in adapting to the loss of functional autonomy and/or the age-related decline [306]. In the latter case, frailty may have caused the depressive syndrome and then become further aggravated by it. The evidence in support in this regard has important implications for the selection of the screening tools, formulation of a correct diagnosis and then planning of the intervention.

The Update of the 2013 ACCF/AHA Guidelines [301] underlines the limited emphasis given so far in the various guidelines to the need to extend educational interventions, which are defined as extremely relevant, also to patients aged over 75 years, actively involving also their caregivers. Finally, it should be underlined that the data from a recent RCT support the effectiveness of cardiac rehabilitation, especially the physical exercise component, in improving the cognitive profile of patients over 75 years old, even in the presence of initial decline [314].

In the panel's opinion, from the literature analysis, as yet still limited, there emerges:

- moderate evidence for the efficacy of interventions of support for depression;

- moderate evidence for the efficacy of psycho-educational and management interventions.

\section{Cardiac patients in palliative care}

Recently the concept of "managed death" has replaced that of "good death" and this important change of paradigm requires all health professionals to have a precise orientation and adequate knowledge [315]:

- End of life refers to patients who may die within 12 months, which ranges from an imminent death perspective (a matter of hours, or days) to a prolonged terminal condition, which in cardiovascular terms essentially concerns advanced CHF.

- End of life care includes care provided to family members after the patient dies.

- In prolonged terminal conditions, there is not always a clear distinction between being sick and dying.

- The transition to end of life care must take place when treatments are no longer effective, the burden of symptoms is extremey heavy and it is necessary to evaluate eventual "disease-exchanging therapies", i.e. a remodulation of treatments in order to allow greater therapeutic investment in the more functional aspects in line with the patient's preferences.

In the cardiovascular field, the natural history of CHF is characterized by a gradual decline in functional capacity, interrupted by acute episodes of instability which further worsen the trend. In ad- 
vanced $\mathrm{CHF}$, or phase D according to AHA, the high rate of mortality is hard to modify, the symptoms are disabling and the quality of life heavily compromised; nevertheless, the prognostic stratification still remains very difficult. Therefore, selecting patients with advanced CHF and a high risk of mortality at 1 year, to shift, at the right time, the goal of treatment from maintenance of life at all costs to alleviation of symptoms and possible improvement in the quality of life requires an integrated approach that takes into account not only the risk scores but also the clinical opinion of all members in the team.

These patients, characterized by complicated symptoms refractory to treatment, by a high level of psychological distress, and by a stringent need to reach shared decisions with their caregivers and family, can benefit greatly from a palliative care approach. [316,317]. In the advanced phase of illness, the patient experiences a marked reduction in their quality of life: from a physical point of view, the symptoms most frequently perceived are fatigue, dyspnea and edema in the limbs. From a psychological point of view, uncertainty and fear and a general sense of imminent death prevail. The sense of threat together with the loss of their family and social role, the physical limitation and the restriction of will and freedom determine profound existential changes. From the awareness of imminent death to the actual death itself, patients go through a series of phases, whose temporal succession varies from individual to individual, during which they pass from the acute crisis of realization to possible acceptance until the final phase of withdrawal into themselves [318].

In the panel's opinion, from the literature analysis, there emerges:

- strong evidence for an association between the following variables and palliative care in cardiac disease:

- Depression

- Distress

- moderate evidence for the association with:

- Anxiety

- Social factors

- mild evidence for the association with:

- Personality factors

\section{PSYCHOLOGICAL INTERVENTIONS}

The statement published in 2012 by the AHA was a real 'call to action' on the need to promote a shared decision-making process with the patient suffering from advanced heart failure [318]. The document illustrates a sort of road map to guide all team members in the activation of a shared decision-making process, precisely during the transition phase, i.e. when the context is increasingly characterized by uncertain prognosis, different outcomes often "competing" with each other, and communication barriers. It is necessary to maintain attention on the clinical evolution of the disease, to adjust expectations and to promptly guide decisions; all the same, uncertainty is unavoidable and needs to be included in discussions with patients and family members. Discussions with patients must take into account all the outcomes, not only that of survival but also those of major adverse events, the burden of symptoms, functional limitations, loss of independence, quality of life and constraints on caregivers.

In the panel's opinion, from the literature analysis, as yet still limited, there emerges strong evidence for:

- Interventions of shared decision making with the patient and family members

- A palliative care approach

\section{Patient caregiver}

In dealing with the topic of caregiving, it is necessary to distinguish between objective and subjective burden. The objective burden is as- sociated with the patient's level of dependence during the different stages of the disease, the caregiver's numerous duties, the frequency of hospital admissions, the need to use devices and/or new equipment [320]. The subjective burden refers to the management of all the negative emotions that the activity of caregiving elicits and is produced by the interaction between the characteristics of the patient's illness and inherent characteristics ofn the caregiver. In the acute phase of hospitalization, the cardiac event is experienced by the family in a traumatic way, in that the family members, including for the most part the spouse, experience a breakdown of their normal way of life and the loss of physical integrity of their loved one. The dominant feelings are fear, anxiety, uncertainty, impotence and loss of control. In the phase of chronicization of the disease and then in the terminal phase, family members tend to neglect their own state of health in devoting themselves to that of the patient and coping with all the other daily needs.

In all phases of the diseases, the following scenarios represent serious challenges:

- the patient's neuro-cognitive symptoms create an added burden for the spouse (321)

- the disease can disturb the couple's sexuality [322]

- if the caregiving spouse is of a young age, the burden can be worse due to the greater number of duties and responsibilities towards other family members, e.g. children and/or parents, and towards work activity, compared to elderly and retired caregivers [321]

- anxiety, depression and the feeling of loss of control of the family member hinder the patient's psychosocial adaptation to the disease [321]

- the personality traits of low optimism and high neuroticism in the spousal caregiver are associated with major depressive symptoms in the patient

- a low level of mutuality in the couple [321] is associated with a high burden of the family member, negatively affecting the caregiving, and with a worse health status of the patient

- lack of social support and the presence of economic problems increase the caregiver's burden [323-325]

Protective factors in all phases of the disease are:

- perception of control and good communication with the healthcare team [326];

- optimism and marital satisfaction and a supportive coping style of the partner [327];

- the possibility of having good social support, possibly sharing the care of the patient with another family member [324, 328];

- the possibility for the couple to receive informative and educational interventions regarding the area of sexuality, to increase their knowledge, well-being and help them maintain an intimate relationship [329].

Below are presented the issues related to the burden in the different phases of illness.

\section{1) Acute phase of the disease (family caregivers of an ischemic and/or CABG patient)}

Caregiver burden may be due to the demand on time (objective time spent) and difficulty with caregiving activities (subjective perceived stress) [330]

- CABG caregivers have reported feeling unprepared for their role and thus are at risk of caregiver burden. Compared to females, male $\mathrm{CABG}$ caregivers had totally different challenges and perceived the organizing of care as more demanding than females. All male caregivers have higher demand (time spent), difficulty (level of stress) and overall burden compared to female caregivers [330]

- Older CABG caregivers (>70 years) are also at risk of greater burden [330] 
- $\quad$ symptoms of PTSD (alarm, hypervigilance, confusion, derealization) in the family caregiver have negative effects on the patient's disease management [331]

Psychological interventions aimed at ischemic patients and their partners improve, in the spouse, the anxiety, knowledge, and satisfaction about care [332]. Family members, particularly wives, young caregivers and with a high educational level, request to participate actively, together with the patient, in the interventions of secondary prevention and in the decision-making processes regarding drug treatment and the change of lifestyle. It is therefore necessary to have interventions of support centered on the person but aimed at the couple in order to reduce anxiety and improve communication and coping skills [326]. These interventions must also be focused on topics such as communication, care, vigilance but also respect for autonomy (family members frequently assume a 'controlling' attitude towards the patient and an attitude of 'neglect' regarding their own needs), changes in family roles and perspectives/expectations regarding the future [331,333].

In order to change lifestyle, the usefulness of motivational interviews with the couple is pointed out - they are effective in identifying processes that perpetuate dysfunctional behaviors, in exploring possible alternatives, and in determining the motivation for change, helping the couple to reflect on the modes of communication ('supportive' $v s$ 'controlling') and promoting the use of 'supportive' communication strategies, with positive effects on the change of risk behaviors for health [334].

\section{2) Chronic phase of illness (family caregivers of a patient with CHF)}

Considering caregiving factors together with patient factors significantly increases our understanding of patient clinical events risk in CHF [335]. The influence of an effective caregiver on CHF patient outcomes has been shown in improved quality of life, lower hospitalization rates [335] and reduced mortality. Psychological distress of the spouse increases the symptoms of heart failure, regardless of the stress perceived by the patient and/or NYHA class [336]. However, providing regular care to a CHF patient can lead to deficits in the caregiver's own health and quality of life. Studies have shown that HF caregivers experience a similar level of burden as caregivers of patients with advanced cancer and chronic obstructive pulmonary disease [Humphrey 2013]. The assistance and care of patients with heart failure is perceived as demanding and characterized by a strong emotional distress with feelings of insecurity and uncertainty, by less personal freedom, experience of solitude, social isolation and often by economic problems [325,337]. The literature indicates that the burden is worse in the presence of certain individual factors and external factors [324].

The main individual dimensions that make caregivers particularly vulnerable are:

- female gender [324]. Female partners of patients with heart failure have a lower quality of life compared to male caregivers and a lower level of well-being in general compared to female partners of healthy people;

- a low perception of control [324,337,323];

- a low quality of life regarding the physical component [338]: caregiving worsens the physical health status of family members with pre-existing health problems.

The main external factors that increase the burden are:

- poor physical and mental health of the patient [324,337,338], frequent emergency hospitalizations [323,324,338], and difficulty in managing symptoms and therapies [338]. The most difficult tasks related to caregiving (monitoring of symptoms, managing medication and behavioral and food indications) contribute significantly to worsening the caregiver's physical health.
The literature regarding interventions for caregivers of patients with heart failure has focused on management, communication and relational aspects to improve the patient's health conditions, as well as on the disease management, but also on the burden of the caregiver. There are different modes of intervention according to the different goals:

- interventions involving patients, family and physicians aimed at improving the patient's disease management in terms of self-care, symptoms monitoring and taking of medications [339].

- interventions focused on the family and on reducing the caregiver's burden aimed at improving the physical and mental health of the patient and relational aspects [340].

- interventions of 'telehealth care' and 'telephone coaching' aimed at improving management of the transition phase to home [341] and at increasing the perceived caregiver mastery [342].

\section{3) Family caregivers of patients undergoing heart trans- plantation}

Relatives take on great responsibilities during patients' heart or lung transplant process and an understanding of their situation is required. Any patient for whom social supports are considered insufficient to achieve compliant care in the outpatient setting may be regarded as having a relative contraindication to transplant [178]. Research has shown that relatives of patients wait-listed for HT worry about a rapid disease progression and death while the patient is waiting for new organs. Most relatives suffer from uncertainty, fear and stress. These emotions persist after the transplantation, during the recovery period, and in some cases for years because of the risk of acute or, in the longer term, chronic organ rejection and death [178]. Poor physical health in the caregiver at 12 months after transplantation results in a lower patient survival during the next seven years [343]. After HT, considering the consequences on the psychophysical health and socio-economic level of caregivers, some authors have identified the need for psychological support to the family [344] and for psychotherapeutic interventions addressed to the family [345]; others, focusing on potential conflicts in the marital relationship, suggest the utility of psychosocial interventions of counseling addressed to the couple [346,347].

\section{4) Family caregivers of patients undergoing implantation of a device}

During the implantation phase, the family lives in a condition of distress characterized by a physical and emotional burden linked to the sense of responsibility, fear, anxiety, and loss of freedom and independence $[348,349]$. There is a higher level of anxiety in the family members than in the patients themselves and about $23 \%$ of caregivers manifest PTSD, which is not found in patients [350]. If the LVAD implant was done in an emergency and, therefore, caregivers and patients could not receive adequate information, the anxiety and fear remain, especially for caregivers, even in the period after the implant itself [349].

\section{5) Family caregivers of patients in the terminal phase}

There are few systematic studies on the families of cardiac patients in the terminal phase of illness [351]. The experience of burden appears to be relatively stable over time, without much differentiation between the phase of chronic disease and the terminal phase, but in the terminal phase the family caregiver of a cardiac patient appears to be characterized by specific needs for information and communication regarding palliative care and decisions on the end of life. Some studies point out that caregivers complain about a lack of information from care personnel regarding the treatment of symptoms, and of prognostic information about the future development of the disease, including end of life issues (e.g., disactivation of ICD), and hence a lack of planning of the timing and services that can support the patient and caregiver in 
the terminal phase of illness [352]. From the literature there emerges a sense of frustration regarding the use, in this phase and by the doctors, of technical jargon difficult to understand [353]. From the analysis of the literature, some considerations emerge:

- young age, female sex and persistent family conflicts are factors associated with greater emotional stress experienced by caregivers [354];

- a fatalistic/anxious coping style [355] of the family caregiver worsens the burden;

- poor social support [354,356], poor help in managing daily activities [357], and family economic problems [355] worsen the patient's disease management;

- an inadequate knowledge/awareness of the terminal status on the part of the family caregiver interferes with the patient's disease management [353];

- the progression of the disease severity increases the limitations in the social relationships of patient and family and aggravates the communication difficulties between the partners [353].

Family members of terminal cardiac patients display similar needs to family members of patients with other terminal diseases; therefore, it is necessary to extend to this group of patients and families the use of specialized palliative care services with a multidisciplinary approach, which must include interventions of psychosocial support and on endof-life management of the patient aimed at family members [352,357].

\section{6) Family caregivers of patients over $\mathbf{7 5}$ years}

The caregivers of patients aged $\geq 75$ years are mostly older women, wives, often also affected by multiple physical age-related disorders and they are distinguished from other groups of caregivers by their older age and consequently greater need for help in daily living activities $[358,359]$. The burden in these caregivers means they have need for help in daily tasks, need for emotional support and a general need for greater communication with both the patient and the doctors [358). The experience of burden seems to depend mostly on characteristics of the caregiver, highlighting their ability to adapt to their own role, their ability to cope and the quality of the previous relationship with the patient [360]. Because family members of patients $>75$ years are often elderly, the main problems are:

- insufficient knowledge/awareness of the patient's illness due to lack of communication with the doctors [358];

- low socio-economic status, poor social support and social isolation [361]. It is essential to focalize interventions on the caregiver in order to provide them with more information and increase their communication with healthcare staff and with the patient [362], promote the pres- ence of an emotional and social support network, increase their capacity of adaptation to the caregiver role through specific interventions that increase the caregiver 's own coping strategies and make them more effective [356]. Indeed, some studies have shown that the experience of caregiving can be experienced not only as a source of stress but also as a positive experience [359], especially when the communication between patient and caregiver is improved, with positive effects on both the management of the disease and on the quality of life of both partners [363], placing at the center of interest the concept of the patient-caregiver dyad [364].

\section{Best practice in psychological activities in CPR}

Best practice is defined as those interventions, programs, or strategies that have, through multiple implementation, demonstrated a high impact (positive changes related to the desired goals, high adaptability, i.e. successful adaptation and transferability to different settings) and high quality of evidence (excellent quality of research/evaluation methodology, confirming the intervention's high impact and adaptability evidence). Best practice is one that is most suitable given the available evidence and particular situation or context. In health promotion, such practices are used to demonstrate what works for enhancing health-related outcomes of individuals and communities, and how and why they work in different situations and contexts [from Canadian Best Practice Portal; accessed on 11 December 2017].

The process of evaluating the goodness of a practice is particularly critical. The approaches and methodologies can be many and various, but there will nevertheless always be a component of subjectivity.

The Panel referred to the following factors of relevance:

- performance $=$ ability of a practice to achieve the objectives (based on data from the literature);

- efficiency and sustainability = ability of a practice to base itself on existing resources and to make efficient use of these resources;

- transferability/reproducibility = exportability of the practice to different contexts;

- learning and relationships $=$ ability of the practice to create relationships and contexts of interdisciplinary learning and collaboration.

By best practice we thus mean a series of general indications of support for each decision-making node in the assessment and intervention, transversal to the different pathologies, based on analysis of the evidence as well as on considerations of a legal and deontological nature (Figure 1).

It is necessary to:

\section{Best practice}

- assess the possible presence of psychopathological aspects in the medical history and consider referring the patient to local community services

- investigate the possible presence of previous cognitive deficits

- evaluate the possible presence of depression and anxiety, either reactive or related to the clinical condition

- evaluate the presence/absence of social support

- evaluate the knowledge, awareness, acceptance and management of the disease

- take into account sex, age and ethnic minorities

- evaluate positive, personal and environmental resources and construct interventions aimed at reinforcing them

- evaluate the level of health literacy of the patient and caregiver in order to personalize the informative, educational and communication intervention

- design psychological interventions of low/high intensity based on the problems detected and the working and organizational resources present

- provide counseling to caregivers where problems are detected and/or their need emerges from the patients themselves, the family and/or the multidisciplinary team

- provide counseling on sexuality, where problems arise

- structure all of the psychological activity within the multidisciplinary intervention and in synergy with the team

Figure 1. General indications of support for each decision-making node in the assessment and intervention, transversal to the different pathologies. 
Following the literature analysis, we were able to define recommendations, according to the grade of evidence: strong $(+++)$, moderate $(++)$, mild $(+)$, of low and high intensity evidence based psychological/psychotherapeutic interventions (Figure 2).

The figure 3 contains operational cards summarizing the assessment and intervention recommendations, disease by disease, according to the grade of evidence: strong $(+++)$, moderate $(++)$, mild $(+)$.

A flow chart is provided showing the path from selection to patient discharge. The selection phase initiates the care process and fea- tures the choice of the service by the user or person referring. The definition of some strategies by the psychologist allows to then guide the requests of the user or person who has referred the patient, especially in terms of appropriateness of access to the process of care (Figure 4).

The figure 5 contains a checklist for the selection of patients to be referred to the psychologist.

The figure 6 lists the recommended psychological and neuropsychological tests.

\begin{tabular}{|c|c|c|c|c|c|c|c|c|c|c|}
\hline Pathologies & 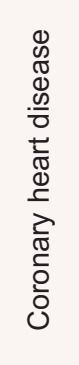 & 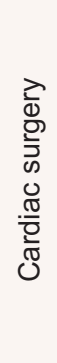 & 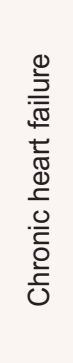 & 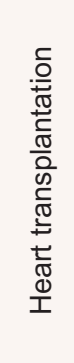 & 1) & $\underline{0}$ & $\begin{array}{l}\text { I } \\
\text { D } \\
\stackrel{0}{0}\end{array}$ & 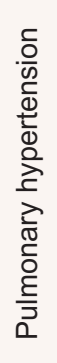 & 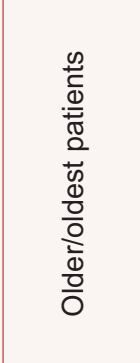 & 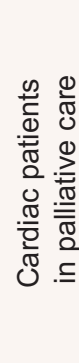 \\
\hline \multicolumn{11}{|l|}{ LOW } \\
\hline $\begin{array}{l}\text { Individual and/or group } \\
\text { counseling (from single } \\
\text { interview to motivational } \\
\text { interview) }\end{array}$ & +++ & $\bullet$ & +++ & +++ & $\bullet$ & +++ & $\bullet$ & $\bullet$ & $\bullet$ & $\bullet$ \\
\hline $\begin{array}{l}\text { Psycho-educational } \\
\text { sessions regarding } \\
\text { psychosocial risk } \\
\text { factors, smoking, } \\
\text { diet, etc. }\end{array}$ & +++ & & ++ & & + & ++ & & & $\begin{array}{l}\text { Only with } \\
\text { costs and } \\
\text { benefits } \\
\text { evaluation }\end{array}$ & \\
\hline $\begin{array}{l}\text { Multidisciplinary } \\
\text { sessions regarding } \\
\text { information } \\
\text { and management } \\
\text { (self-care, } \\
\text { self-management, } \\
\text { self-help, telemedicine) }\end{array}$ & +++ & & +++ & + & & ++ & & & $\begin{array}{l}\text { Only with } \\
\text { costs and } \\
\text { benefits } \\
\text { evaluation }\end{array}$ & \\
\hline \multicolumn{11}{|l|}{ HIGH } \\
\hline $\begin{array}{l}\text { Psychotherapy } \\
\text { interventions: individual, } \\
\text { group (stress } \\
\text { management) or family } \\
\text { (at least } 1 / \text { week) * }\end{array}$ & +++ & + & ++ & ++ & + & +++ & $\bullet$ & $\bullet$ & $\bullet$ & $\bullet$ \\
\hline $\begin{array}{l}\text { Multidisciplinary } \\
\text { interventions: evidence } \\
\text { of the need to } \\
\text { implement a structured } \\
\text { psychotherapeutic } \\
\text { intervention } \\
\text { (cognitive-behavioral } \\
\text { therapy, motivational, } \\
\text { mindfulness, etc.) }\end{array}$ & +++ & & ++ & & & ++ & & & $\bullet$ & \\
\hline
\end{tabular}

Figure 2. Low and high intensity evidence based psychological/psychotherapeutic interventions in the different cardiac pathologies. 


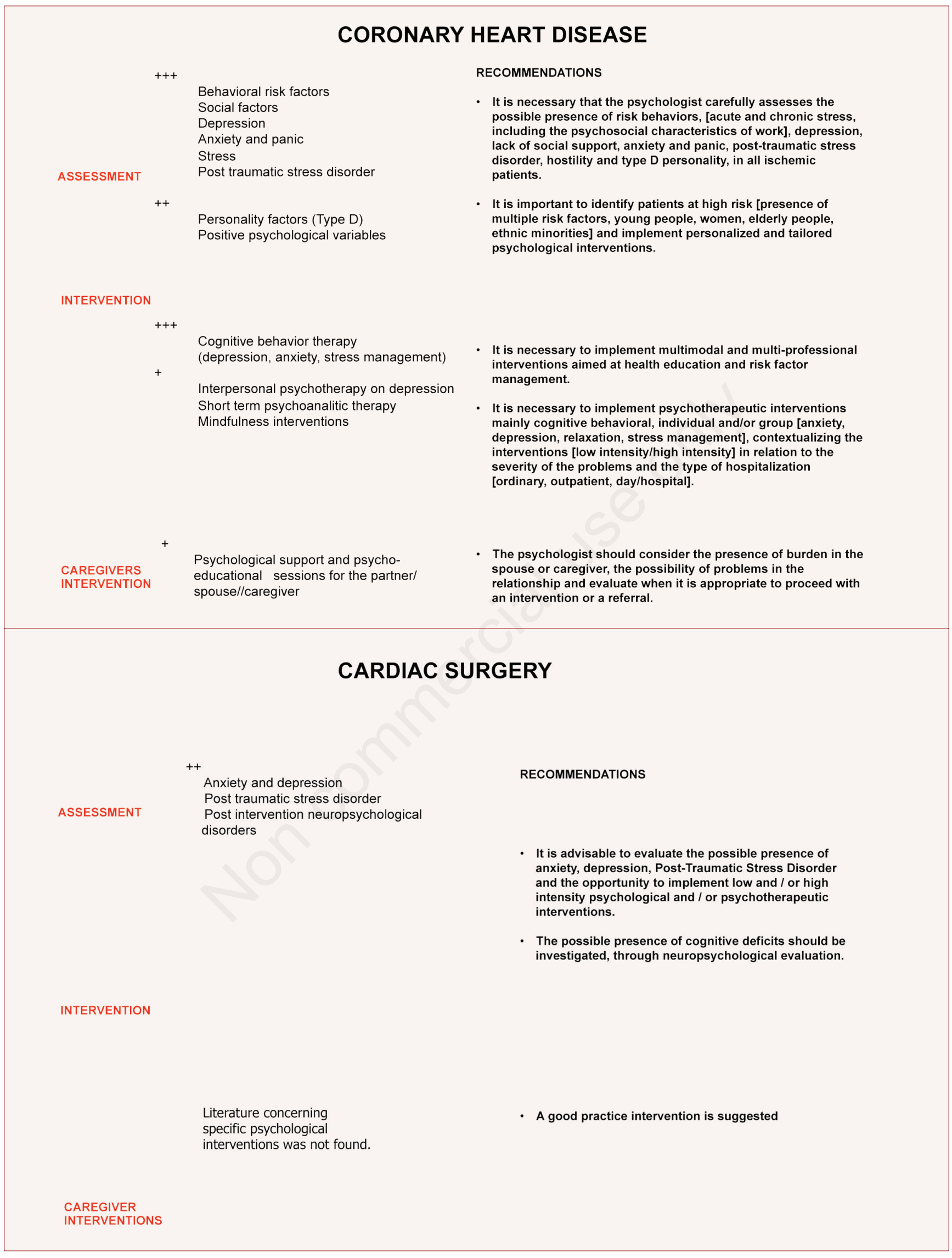

Figure 3. Operational cards. 


\section{CHRONIC HEART FAILURE}

$\begin{array}{lll} & & \\ & & \begin{array}{l}\text { Depression } \\ \text { Addiction alcohol and cocaine } \\ \text { Anxiety }\end{array} \\ & ++ & \text { Social factors } \\ \text { ASSESSMENT } & & \begin{array}{l}\text { Personality factors (type D) } \\ \text { Neuropsychological disorders } \\ \text { Sleep disorders } \\ \text { Disease management }\end{array} \\ & \text { Positive psychological variables }\end{array}$

$++$

Cognitive-behavioral interventions Psychoeducational and disease management interventions (self care) Telemedicine

\section{RECOMMENDATIONS}

- It is necessary that the psychologist carefully assess the possible presence of depression, anxiety, the abuse of cocaine or alcohol in remote and / or recent anamnesis, the lack of socio-family support, low SES and the immigrant status.

- Cognitive deficits in the elderly and severely compromised patients should be investigated by neuropsychological evaluation

- The psychologist should evaluate the levels of health literacy, adherence and self-management skills of the disease to optimize the outcome, prevent relapse and avoid rehospitalization.

- Evaluation of the presence of Type-D personality is not recommended routinely

- Both multidisciplinary and nursing management and telemedicine intervention programs must be structured with cognitive-behavioral techniques, since they reduce the number of hospitalizations and the mortality for SCC [low intensity]

- Psychological interventions are necessary in the presence of depression, anxiety and lack of emotional support [high intensity]

It is necessary for the psychologist to consider when it is appropriate to make a referral to the social worker.

- Psychological intervention should optimize management treatment, encourage self-management resources and improve adherence to prescriptions.

- Health education should be directed to self-management of the SCC not only in terms of behavioral changes, but also changes in personal beliefs to achieve long-term lasting changes.

- The psychologist should consider the presence of burden in the spouse or caregiver, the possibility of problems in the relationship and evaluate when it is appropriate to proceed with an intervention or a referral.

- In order to encourage and maintain knowledge and mastery in the management of the disease, psychological, psychoeducational and behavioral interventions are needed on the family members
CAREGIVERS INTERVENTION
Psychological support and psychoeducational interventions in family members

Caregiver burden interventions

\section{HEART TRANSPLANTATION}

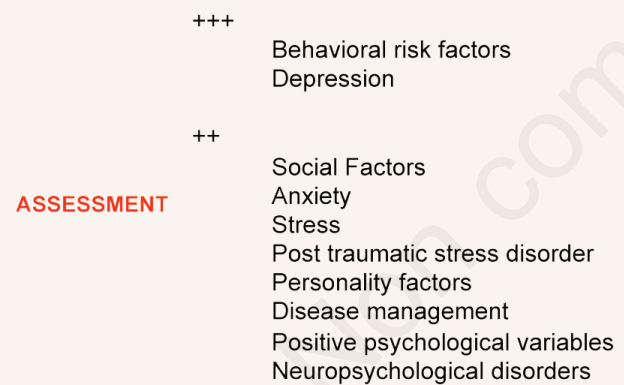

INTERVENTION

$$
\begin{gathered}
\text { Cognitive-behavioral interventions } \\
++\quad \begin{array}{l}
\text { Psycho-educational and management } \\
\text { interventions }
\end{array}
\end{gathered}
$$

\section{RECOMMENDATIONS}

- For all cardiac transplant patients, a psychodiagnostic and psychosocial investigation is required to identify the possible presence of prior psychiatric pathology, stress, anxiety and reactive depression and psychosocial distress.

- If clinically indicated, in cardiac transplant patients, it is necessary to perform a neuropsychological assessment of cognitive deficits, that are possible contraindications to transplantation [with particular attention to the executive functions involved in the decision making process].

- It is necessary a careful assessment of behavioral risk factors (alcohol, tobacco, obesity), possible contraindications to transplantation.

- It is necessary to structure a psycho-educational program aimed at facilitating the understanding and adherence to clinical, pharmacological, behavioral prescriptions and substances de-addiction, in the pre and post-transplant phase.

- It is necessary to implement low and / or high intensity psychological and / or psychotherapeutic interventions in relation to the severity of the problems emerging and of the hospitalization regimen [ordinary, outpatient, day / hospital, both in the pre-transplant and in the post-transplant phases.

- The psychologist should consider the presence of burden in the spouse or caregiver, the possibility of problems in the relationship and evaluate when it is appropriate to proceed with an intervention or a referral.

Figure 3. Continued from previous page. 


\title{
MECHANICAL VENTRICULAR ASSIST DEVICES
}

\begin{tabular}{|c|c|c|}
\hline & & RECOMMENDATIONS \\
\hline ASSESSMENT & $\begin{array}{l}\text { Depression } \\
\text { Anxiety } \\
\text { Acute and chronic stress } \\
\text { Psychophysiological disorders of sleep } \\
\text { Cognitive deficits }\end{array}$ & $\begin{array}{l}\text { It is necessary that the psychologist carefully assesses the } \\
\text { possible presence of anxiety, depression, distress, sleep } \\
\text { disorders, in the pre and post-implantation phases of L-VAD. } \\
\\
\text { The possible presence of cognitive deficits should be } \\
\text { investigated through neuropsychological evaluation. }\end{array}$ \\
\hline INTERVENTION & $\begin{array}{l}\text { Cognitive-behavioral interventions } \\
\text { Psycho-educational and } \\
\text { management interventions }\end{array}$ & $\begin{array}{l}\text { It is important to promote psycho-educational interventions to } \\
\text { increase awareness and the ability to manage L-VAD both in } \\
\text { patients and in their caregivers. } \\
\text { - It is necessary to implement low and / or high intensity } \\
\text { psychological and / or psychotherapeutic interventions in } \\
\text { relation to the severity of the emerging problems and of the } \\
\text { hospitalization regimen [ordinary, outpatient, day / hospital, both } \\
\text { in the pre-implant and in the post phases. }\end{array}$ \\
\hline
\end{tabular}

The psychologist should consider the presence of burden in the spouse or caregiver, the possibility of problems in the

\section{IMPLANTABLE CARDIOVERTER DEFIBRILLATOR}

\author{
RECOMMENDATIONS
}

$++$

Depression

ASSESSMENT Anxiety

Post-traumatic stress disorder

Type D personality

Cognitive deficits
- It is necessary to evaluate the presence of post-traumatic stress disorder [PTSD]

- An evaluation of patients who experienced shock [appropriate and inappropriate] is recommended.
INTERVENTION

$+++$

psychotherapeutic interventions, mainly cognitive-behavioral, integrated with mindfulness and relaxation techniques

$++$

psychoeducational interventions psychological support
- Psychoeducational interventions are recommended [low intensity)

- It is necessary that patients with ICD, in which psychopathological symptoms have emerged, are supported with psychotherapeutic interventions (high intensity), mainly cognitive behavioral ones, integrated with mindfulness and relaxation techniques.

- Information on the possibility of disabling the ICD should be shared with patients

Figure 3. Continued from previous page. 


\section{PULMONARY HYPERTENSION}

\begin{tabular}{|c|c|c|}
\hline & & RECOMMENDATIONS \\
\hline ASSESSMENT & $\begin{array}{l}+ \\
\text { Depression } \\
\text { Anxiety / Panic } \\
\text { Psychophysiological disorders of sleep }\end{array}$ & $\begin{array}{l}\text { It is necessary to evaluate the possible presence of anxiety, } \\
\text { depression and sleep disorders associated with the clinical } \\
\text { condition }\end{array}$ \\
\hline
\end{tabular}

INTERVENTION

there are no studies indicating

efficacy of psychological

interventions
A good practice intervention is suggested

- The implementation of low and / or high intensity psychological and $/$ or psychotherapeutic interventions in relation to the severity of the emerging problems and the hospitalization regimen [ordinary, outpatient, day / hospital] is suggested

- Counseling for family caregivers is suggested.

- It is necessary to provide psychological counseling on the issue of pregnancy

\section{GROWN-UP CONGENITAL HEART}

INTERVENTION

RECOMMENDATIONS

$++$

Social factors

ASSESSMENT Depression

Anxiety

Knowledge, representation, awareness of the disease
- Assessment and psychological interventions would be desirable in the grown-up congenital heart patients in rehabilitation

- It is necessary to check if the surgical scar has caused problems for the patient [especially in the female population].

- A good practice intervention is suggested

emerges mild evidence of efficacy (a single psychological intervention)

- It is necessary to provide psychological counseling on the issue of pregnancy 


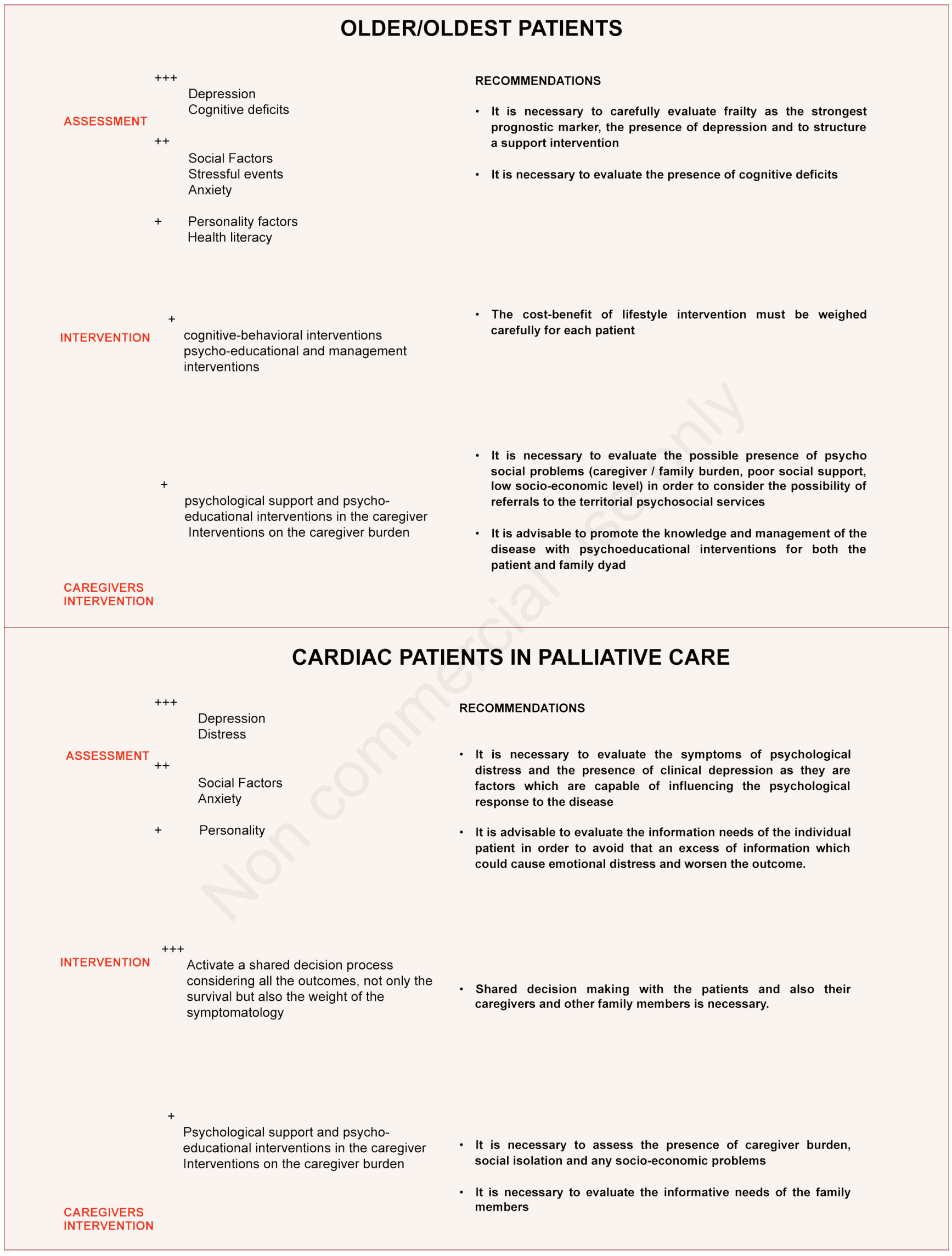

Figure 3. Continued from previous page. 


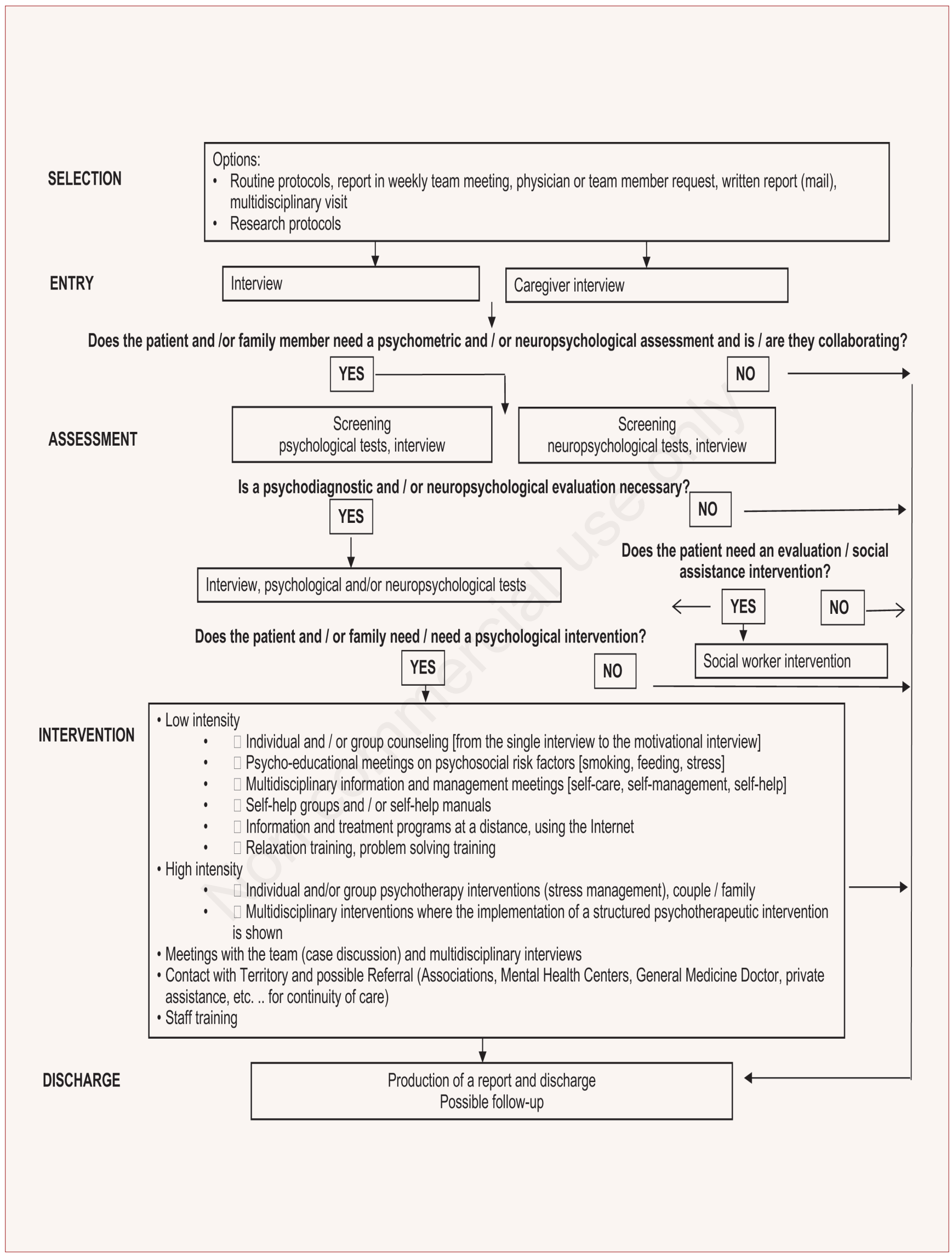

Figure 4. Flow chart showing the path from selection to patient discharge. 
SELECTION CHECKLIST For each area, assess the presence/absence of the listed problems: it is sufficient to find only one element to make the psychological intervention necessary.

1) PSYCHOLOGICAL COMORBIDITIES

YES $\square \quad$ NO $\square$

$\checkmark$ Depression (during the last month the patient felt down and hopeless? he lost interest and pleasure in life?) Anxiety (during the last month the patient has had sudden fears or panic? is frequently unable to stop or control worrying?)

$\checkmark$ Post-traumatic stress disorder (during the last month the patient has been exposed to a traumatic event? he suffers from nightmares or intrusive thoughts?)

$\checkmark$ Type D personality factors, Hostility (in general the patient feel anxious, irritable, or depressed? he tends to avoid sharing his thoughts and feelings with other people?)

2) SPECIFIC PSYCHOLOGICAL ISSUES

YES $\square \quad$ NO $\square$

$\checkmark$ Neuropsychological disorders (the patient is cognitively impaired?)

$\checkmark$ Acute or chronic mental stress (the patient refers defeat or other serious life events?)

$\checkmark$ Chronic stress at work (the patient refers long working hours, extensive overtime work, high psychological demands, unfairness and job strain?)

$\checkmark$ Problems regarding the area of sexuality

3) DISEASE MANAGEMENT / SOCIAL ISSUES/ CAREGIVER NEEDS Y YES $\square \quad$ NO $\square$

$\checkmark$ Inadequate awareness and acceptance of the disease, inadequate treatment adherence (the patient has impaired illness awareness and treatment related prejiudices?)

$\checkmark$ Social isolation and low socio-economic status (the patient is living alone, in a poor residential area? is isolated and disconnected from others? He has a low educational level, a low income?)

$\checkmark$ Caregiver needs / burden (the caregiver needs information, emotional support? The care of patients is perceived as demanding and characterized by a strong emotional distress and by economic problems?)

Figure 5. Checklist for the selection of patients to be referred to the psychologist.

Psychological and neuropsychological screening tests. References and description of the tools are available in www.gicr.it in the psychological area-tools section

- Anxiety and Depression-Revised [AD-R]

- Hospital Anxiety and Depression Scale [HADS]

- Beck Depression Inventory-2 [BDI-2]

- Patient Health Questionnaire 9 [PHQ-9]

- Generalized Anxiety Disorder 7 [GAD-7]

- Mini Mental State Examination [MMSE]

- Montreal Cognitive Assessment [MoCA]

- Addenbrooke's Cognitive Examination Revised [ACE-R]

- Clinical Outcomes in Routine Evaluation Outcome Measure (CORE-OM)

- Distress Scale [DS14, Type D personality]

- Maugerl CaRdiac preventiOn-Questionnaire [MICRO-Q]

- Adherence Schedule in Heart Disease-Brief [ASHiD-R]

- Family Strain Questionnaire [FSQ]

- Disease Impact On Caregiver [DIOC]

Figure 6. Psychological and neuropsychological tests. 


\section{Conclusions}

This paper aims to support all psychologists working with CPR patients in identifying good practice and disease-specific models of intervention. There is, however, a need to develop new models of research that 'photograph' the real world of patients (registers, etc.), often quite different from the selected populations present in clinical trials. Some recommendations can be made for future research:

- to use and develop new validated "cross cultural" instruments;

- to promote observational studies (registers) that reflect the 'real world';

- to develop RCTs, robustly designed and with adequate follow-up, to evaluate the efficacy of the psychological/psychotherapeutic therapies described in this position paper on psychological and cardiovascular endpoints, focused on specific patient groups (in particular, women and the elderly);

- to develop research on cardiac patients in palliative care;

- to promote studies to evaluate the dedicated caregiver program with a large, representative, diversified sample that incorporates information and resources tailored to the specific concerns and needs of caregivers, in various age and gender cohorts.

Future research should validate concerns in more diverse samples so that interventions can be targeted to better support male and female caregivers in the various age-groups.

According to Richards [7], future large-scale trials testing the effectiveness of psychological therapies are required due to the uncertainties within the evidence. Future trials would benefit from testing the impact of specific (rather than multifactorial) psychological interventions on patients with $\mathrm{CHD}$, and testing the targeting of interventions to different patient populations (i.e., people with CHD, with or without psychopathologies).

\section{References}

1. Sommaruga M, Tramarin R, Angelino E, et al. Task Force per le Attività di Psicologia in Cardiologia Riabilitativa e Preventiva, Gruppo Italiano di Cardiologia Riabilitativa e Preventiva. Guidelines for psychology activities in cardiologic rehabilitation and prevention. Monaldi Arch Chest Dis 2003;60:184-234 [Article in Italian].

2. Griffo R, Tramarin R, Volterrani $M$, et al. Società Italiana Cardiologia Ospedalita Accreditata. [The Italian Survey on Cardiac Rehabilitation - 2013 (ISYDE.13-Directory): national availability and organization of cardiac rehabilitation facilities]. G Ital Cardiol 2016 17:217-24 [Article in Italian].

3. Ladwig KH, Lederbogen F, Albus C, et al. Position paper on the importance of psychosocial factors in cardiology: update 2013. Ger Med Sci 2014;12:09.

4. Rozanski A. Behavioral cardiology: current advances and future directions. J Am Coll Cardiol 2014;64:100-10.

5. Pogosova N, Saner H, Pedersen SS, et al. Psychosocial aspects in cardiac rehabilitation: from theory to practice. A position paper from the Cardiac Rehabilitation Section of the European Association of Cardiovascular Prevention and Rehabilitation of the European. Society of Cardiology. Eur J Prev Cardiol 2015;22:1290-306.

6. Piepoli MF, Hoes AW, Agewall S, et al. 2016 European guidelines on cardiovascular disease prevention in clinical practice. The Sixth Joint Task Force of the European Society of Cardiology and Other Societies on Cardiovascular Disease Prevention in Clinical Practice (constituted by representatives of 10 societies and by invited experts. Developed with the special contribution of the
European Association for Cardiovascular Prevention \& Rehabilitation]. G Ital Cardiol 2017;18:547-612.

7. Richards SH, Anderson L, Jenkinson CE, et al. Psychological interventions for coronary heart disease. Cochrane Database Syst Rev 2017;4:CD002902.

8. Roncella A, Pristipino C. Psychotherapy for ischemic heart disease. An evidence-based clinical approach. Springer; 2016.

9. Riegel B. State of the science: promoting self-care in persons with Heart Failure: a scientific statement from the American Heart Association. Circulation 2009;120:1141-63.

10. Clark DM. Implementing NICE guidelines for the psychological treatment of depression and anxiety disorders: the IAPT experience. Int Rev Psychiatry 2011;23:318-27.

11. Baer JS, Marlatt GA, McMahon RJ. Addictive behaviors across the life span: prevention. Treatment and Policy issues. Beverly Hills: Sage; 1993.

12. Bonomo C, De Isabella G. Lavorare sull'indicazione clinica e lo Stepped Care. In: Biffi G, De Isabella G. Nuove Sfide per la Salute Mentale, Maggioli Editore; 2013.

13. Layard R, Clark D, Knapp M, Mayraz G. Cost benefit analysis of psychological therapy. National Institute Economic Review 2007;202:90-8.

14. Richards DA, Suckling R. Improving access to psychological therapy. Clin Psychol Forum 2008;181:9-16.

15. Gyani A, Shafran R, Layard R, Clark DM. Enhancing recovery rates: Lessons from year one of IAPT. Behav Res Ther 2013;51:597-606.

16. Radhakrishnan M, Hammond G, Jones PB, Watson A. Cost of Improving Access to Psychological Therapies (IAPT) programme: An analysis of cost of session, treatment and recovery in selected Primary Care Trusts in the East of England region. Behav Res Ther 2013;51:37-45.

17. Lichtman JH, Froelicher ES, Blumenthal JA, et al. Depression as a risk factor for poor prognosis among patients with acute coronary syndrome: systematic review and recommendations: a scientific statement from the American Heart Association. Circulation 2014;129:1350-69.

18. Peters A, McEwen BS. Stress habituation, body shape and cardiovascular mortality. Neurosci Biobehav Rev 2015;56:139-50.

19. Tully PJ, Cosh SM, Baumeister H. The anxious heart in whose mind? A systematic review and meta-regression of factors associated with anxiety disorder diagnosis, treatment and morbidity risk in coronary heart disease. J Psychosom Res 2014;77:439-48.

20. Pedersen SS, von Känel R, Tully PJ, Denollet J. Psychosocial perspectives in cardiovascular disease. Eur J Prev Cardiol 2017;24:108-15.

21. Sofi F, Cesari F, Casini A, et al. Insomnia and risk of cardiovascular disease: a meta-analysis. Eur J Prev Cardiol 2014;21:57-64.

22. Cappuccio FP, Cooper D, D’Elia L, et al. Sleep duration predicts cardiovascular outcomes: a systematic review and meta-analysis of prospective studies. Eur Heart J 2011;32:1484-92.

23. Ronksley PE, Brien SE, Turner BJ, et al. Association of alcohol consumption with selected cardiovascular disease outcomes: a systematic review and meta-analysis. BMJ 2011;342:d671.

24. Holmes MV, Dale CE, Zuccolo L, et al. Association between alcohol and cardiovascular disease: Mendelian randomisation analysis based on individual participant data. BMJ 2014;349:g4164.

25. Goel S, Sharma A, Garg A. Effect of alcohol consumption on cardiovascular health. Curr Cardiol Rep 2018;20:19.

26. Stankowsky RV, Kloner RA, Rezkala SH. Cardiovascular consequences of cocaine use. Trends in Cardiovasc Med 2015;25:517-26. 
27. Marmot M. Social determinants of health inequalities. Lancet 2005;365:1099-104.

28. Albert MA, Glynn RJ, Buring J, Ridker PM. Impact of traditional and novel risk factors on the relationship between socioeconomic status and incident cardiovascular events. Circulation 2006;114:2619-626.

29. Mackenbach JP, Stirbu I, Roskam AJ, et al. Socioeconomic inequalities in health in 22 European countries. N Engl J Med 2008;358:2468-81.

30. Stringhini S, Sabia S, Shipley M, et al. Association of socioeconomic position with health behaviors and mortality. JAMA 2010;303:1159-66.

31. Woodward M, Brindle P, Tunstall-Pedoe H. Adding social deprivation and family history to cardiovascular risk assessment: the ASSIGN score from the Scottish Heart Health Extended Cohort (SHHEC). Heart 2007;93:172-6.

32. Alter DA, Franklin B, Ko DT, et al. Socioeconomic status, functional recovery, and long-term mortality among patients surviving acute myocardial infarction. PLoS One 2014;8:e65130.

33. Gerber Y, Goldbourt U, Drory Y. Interaction between income and education in predicting long-term survival acute myocardial infarction. Eur J Cardiovasc Prev Rehabil 2008;15:526-32.

34. Barth J, Schneider S, von Kanel R. Lack of social support in the etiology and the prognosis of coronary heart disease: A systematic review and meta-analysis. Psychosom Med 2010;72:229-38.

35. Holt-Lunstad J, Smith TB, Layton JB. Social relationships and mortality risk: a meta-analytic review. PLoS Med 2010;7:e1000316.

36. Nicholson A, Kuper H, Hemingway H. Depression as an aetiologic and prognostic factor in coronary heart disease: A meta-analysis of 6362 events among 146538 participants in 54 observational studies. Eur Heart J 2006;27:2763-74.

37. Leung YW, Flora DB, Gravely S, et al. The impact of premorbid and postmorbid depression onset on mortality and cardiac morbidity among patients with coronary heart disease: meta-analysis. Psychosom Med 2012;74:786-801.

38. Williams JE, Mosley TH Jr, Kop WJ, et al. Vital exhaustion as a risk factor for adverse cardiac events (from the Atherosclerosis Risk In Communities [ARIC] study). Am J Cardiol 2010;105:1661-5.

39. Schnohr P, Marott JL, Kristensen TS, Get al. Ranking of psychosocial and traditional risk factors by importance for coronary heart disease: the Copenhagen City Heart Study. Eur Heart J 2015;36:1385-93.

40. Roest AM, Martens EJ, Denollet J, et al. Prognostic association of anxiety post myocardial infarction with mortality and new cardiac events: a meta-analysis. Psychosom Med 2010;72:563-69.

41. Roest AM, Martens EJ, de Jonge P, Denollet J. Anxiety and risk of incident coronary heart disease: a meta-analysis. J Am Coll Cardiol 2010;56:38-46.

42. Martens EJ, de Jonge P, Na B, et al. Scared to death? Generalized anxiety disorder and cardiovascular events in patients with stable coronary heart disease: the Heart and Soul Study. Arch Gen Psychiatry 2010;67:750-8.

43. Roest AM, Zuidersma M, de Jonge P. Myocardial infarction and generalised anxiety disorder: 10-year follow-up. Br J Psychiatry 2012;200:324-9.

44. Tully PJ, Cosh SM, Baumeister H. The anxious heart in whose mind? A systematic review and meta-regression of factors associated with anxiety disorder diagnosis, treatment and morbidity risk in coronary heart disease. J Psychosom Res 2014;77:439-48.

45. Nawrot TS, Perez L, Kunzli N, et al. Public health importance of triggers of myocardial infarction: a comparative risk assessment. Lancet 2011;377:732-40.
46. Mostofsky E, Penner EA, Mittleman MA. Outbursts of anger as a trigger of acute cardiovascular events: a systematic review and meta-analysis. Eur Heart J 2014;35:1404-10.

47. Eller NH, Netterstrøm B, Gyntelberg F, et al. Work-related psychosocial factors and the development of ischemic heart disease: a systematic review. Cardiol Rev 2009;17:83-97.

48. Kivimäki M, Nyberg ST, Batty GD, et al; IPD-Work Consortium. Job strain as a risk factor for coronary heart disease: a collaborative meta-analysis of individual participant data. Lancet 2012;380:1491-7.

49. Kivimaki M, Jokela M, Nyberg ST, et al. Long working hours and risk of coronary heart disease and stroke: a systematic review and meta-analysis of published and unpublished data for 603838 individuals. Lancet 2015;386:1739-46.

50. Virtanen M, Nyberg ST, Batty GD, et al. Perceived job insecurity as a risk factor for incident coronary heart disease: systematic review and meta-analysis. BMJ 2013;347:f4746.

51. Roelfs DJ, Shor E, Davidson KW, et al. Losing life and livelihood: a systematic review and metaanalysis of unemployment and allcause mortality. Soc Sci Med 2011;72:840-54.

52. Rich-Edwards JW, Mason S, Rexrode K, et al. Physical and sexual abuse in childhood as predictors of early-onset cardiovascular events in women. Circulation 2012;126:920-7.

53. Keller A, Litzelman K, Wisk LE, et al. Does the perception that stress affects health matter? The association with health and mortality. Health Psychol 2012;31:677-84.

54. Jamieson JP, Nock MK, Mendes WB. Mind over matter: reappraising arousal improves cardiovascular and cognitive responses to stress. J Exp Psychol Gen 2012;141:417-22.

55. Rocha LP, Peterson JC, Meyers B, et al. Incidence of posttraumatic stress disorder (PTSD) after myocardial infarction (MI) and predictors of ptsd symptoms post-MI - A brief report. Int J Psychiatry Med 2008;38:297-306.

56. Edmondson D, Richardson S, Falzon L, et al. Posttraumatic stress disorder prevalence and risk of recurrence in acute coronary syndrome patients: A meta-analytic review. PLoS One 2012;7:e38915.

57. Vaccarino V, Goldberg J, Rooks C, S et al. Post-traumatic stress disorder and incidence of coronary heart disease: A twin study. J Am Coll Cardiol 2013;62:970-8.

58. Tulloch H, Greenman PS, Tassé V. Post-traumatic stress disorder among cardiac patients: Prevalence, risk factors, and considerations for assessment and treatment. Behav Sci (Basel) 2014;5:27-40.

59. Chida Y, Steptoe A. The association of anger and hostility with future coronary heart disease: a meta-analytic review of perspective evidence. J Am Coll Cardiol 2009;53:936-46.

60. Denollet J. DS14: Standard assessment of negative affectivity, social inhibition, and Type D personality. Psychosom Med 2005;67:89-97.

61. Grande G, Romppel M, Barth J. Association between type D personality and prognosis in patients with cardiovascular diseases: A systematic review and meta analysis. Ann Behav Med 2012;43:299-310.

62. Denollet J, Schiffer AA, Spek V. A general propensity to psychological distress affects cardiovascular outcomes. Circ Cardiovasc Qual Outcomes 2010;3:546-57.

63. O'Dell KR, Masters KS, Spielmans GI, et al. Does type-D personality predict outcomes among patients with cardiovascular disease? A meta-analytic review. J Psychosom Res 2011;71:199-206.

64. Coyne JC, Jaarsma T, Luttik ML, et al. Lack of prog- nostic value of type D personality for mortality in a large sample of heart failure patients. Psychosom Med 2011;73:557-62.

65. Grande G, Romppel M, Vesper JM, et al. Type D per- sonality and all-cause mortality in cardiac patients-data from a German cohort study. Psychosom Med 2011;73:548-56. 
66. Versteeg H, Spek V, Pedersen SS, et al. Type D person- ality and health status in cardiovascular disease popula- tions: A metaanalysis. Eur J Prev Cardiol 2012;19:1373-80.

67. Sommaruga M. [Affettività positiva e salute cardiovascolare]. Monaldi Arch Chest Dis 2010;74:1-8 [Article in Italian].

68. Steptoe A, Dockray S, Wardle J. Positive affect and psychobiological processes relevant to health. Journal Personality 2009;77:1747-76.

69. Endrighi R, Hamer M, Steptoe A. Associations of trait optimism with diurnal neuroendocrine activity, cortisol responses to mental stress, and subjective stress measures in healthy men and women. Psychosom Med 2011;73:672-8.

70. Ikeda A, Schwartz J, Peters JL, et al. Optimism in relation to inflammation and endothelial dysfunction in older men: the VA Normative Aging Study. Psychosom Med 2011;73:664-71.

71. Grossardt BR, Bower JH, Geda YE, et al. Pessimistic, anxious, and depressive personality traits predict all-cause mortality: the Mayo Clinic Cohort Study of Personality and Aging. Psychosom Med 2009;71:491-500.

72. Tindle HA, Chang YF, Kuller LH, et al. Optimism, cynical hostility, and incident coronary heart disease and mortality in the Women's Health Initiative. Circulation 2009;120:656-62.

73. Nabi H, Koskenvuo M, Singh-Manoux A, et al. Low pessimism protects against stroke: the Health and Social Support (HeSSup) prospective cohort study. Stroke 2010;41:187-90.

74. Kim ES, Park N, Peterson C. Dispositional optimism protects older adults from stroke: the Health and Retirement Study. Stroke 2011;42:2855-9.

75. Ye S, Denton EG, Wasson LT, Davidson KW. Epidemiology and management of depression following coronary heart disease diagnosis in women. Curr Cardiovasc Risk Rep 2012;6:210-18.

76. Low CA, Thurston RC, Matthews KA. Psychosocial factors in the development of heart disease in women: current research and future directions. Psychosom Med 2010;72:842-54.

77. Shanmugasegaram S, Russell KL, Kovacs AH, et al. Gender and sex differences in prevalence of major depression in coronary artery disease patients: a meta-analysis. Maturitas 2012;73:305-11.

78. Doering LV, Eastwood JA. A literature review of depression, anxiety, and cardiovascular disease in women. J Obstet Gynecol Neonatal Nurs 2011;40:348-61.

79. Möller-Leimkühler AM. Women with coronary artery disease and depression: a neglected risk group. World J Biol Psychiatry 2008;9:92-101.

80. Blom M, Georgiades A, Janszky I, et al. Daily stress and social support among women with CAD results from a 1-year randomized controlled stress management intervention study. Int J Behav Med 2009;16:227-35.

81. Whalley B, Thompson DR, Taylor RS. Psychological interventions for coronary heart disease: cochrane systematic review and metaanalysis. Int J Behav Med 2014;21:109-21.

82. Linden W, Phillips MJ, Leclerc J Psychological treatment of cardiac patients a meta-analysis. Eur Heart J 2007;28:2972-84.

83. Welton NJ, Caldwell DM, Adamopoulos E, Vedhara K Mixed treatment comparison meta-analysis of complex interventions psychological interventions in coronary heart disease. Am J Epidemiol 2009;169:1158-65.

84. Dickens C, Cherrington A, Adeyemi I, et al. Characteristics of psychological interventions that improve depression in people with coronary heart disease: a systematic review and metaregression. Psychosom Med 2013;75:211-21.

85. Van Dixhoorn J, White A. Relaxation therapy for rehabilitation and prevention in ischaemic heart disease: a systematic review and meta-analysis. Eur J Cardiovasc Prev Rehabil 2005;12:193-202.
86. Biondi-Zoccai G, Mazza M, Roever L, et al. Evidence-based psychotherapy in ischemic heart disease: Umbrella review and updated meta-analysis. In: A. Roncella, C. Pristipino (eds.) Psychotherapy for ischemic herat disease. An evidence-based clinical approach. Springer; 2016; pp 131-158.

87. Berkman LF, Blumenthal J, Burg, et al. Effects of treating depression and low perceived social support on clinical events after myocardial infarction: the enhancing recovery in coronary heart disease patients (ENRICHD) randomized trial. JAMA 2003;289:3106-16.

88. Sebregts EH, Falger PR, Appels A, et al. Psychological effects of a short behavior modification program in patients with acute myocardial infarction or coronary artery bypass grafting. A randomized controlled trial. J Psychosom Res 2005;58:417-24.

89. Blumenthal JA, Sherwood A, Babyak MA, et al. Effects of exercise and stress management training on markers of cardiovascular risk in patients with ischaemic heart disease: a randomized controlled trial. J Am Med Assoc 2005;293:1626-34.

90. McLaughlin TJ, Aupont 0, Bambauer KZ, et al. Improving psychologic adjustment to chronic illness in cardiac patients. The role of depression and anxiety. J Gen Intern Med 2005;20:1084-90.

91. Michalsen A, Grossman P, Lehmann N, et al. Psychological and quality-of-life outcomes from a comprehensive stress reduction and lifestyle program in patients with coronary artery disease: results of a randomized trial. Psychother Psychosom 2005;74:344-52.

92. Claesson M, Birgander LS, Lindahl B, et al. Women's hearts — stress management for women with ischemic heart disease: explanatory analyses of a randomized controlled trial. J Cardiopulm Rehabil 2005;25:93-102.

93. Edelman D, Oddone E, Liebowitz RS, et al. A multidimensional integrative medicine intervention to improve cardiovascular risk. J Gen Intern Med 2006;21:728-34.

94. Koertge J, Janszky I, Sundin 0, et al. Effects of a stress management program on vital exhaustion and depression in women with coronary heart disease: a randomized controlled intervention study. J Intern Med 2008;263:281-93.

95. Neves A, Alves AJ, Ribeiro F, et al. The effect of cardiac rehabilitation with relaxation therapy on psychological, hemodynamic, and hospital admission outcome variables. J Cardiopulm Rehabil Prev 2009;29:304-9.

96. Orth-Gomér K, Schneiderman N, Wang HX, et al. Stress reduction prolongs life in women with coronary disease: the Stockholm Women's Intervention Trial for Coronary Heart Disease (SWITCHD). Circ Cardiovasc Qual Outcomes 2009;2:25-32.

97. Blom M, Georgiades A, Janszky I et al. Daily stress and social support among women with CAD: results from a 1-year randomized controlled stress management intervention study. Int J Behav Med 2009;16:227-35.

98. Albus C, Theissen P, Hellmich M, et al. Long-term effects of a multimodal behavioral intervention on myocardial perfusion - a randomized controlled trial. Int J Behav Med 2009;16:219-26.

99. Griffiths K, Camic PM, Hutton JM. Participant experiences of a mindfulness-based cognitive therapy group for cardiac rehabilitation. J Health Psychol 2009;14:675-81.

100. Gulliksson M, Burell G, Vessby B, et al. Randomized controlled trial of CBT vs. standard treatment to prevent recurrent cardiovascular events in patients with coronary heart disease. Secondary Prevention in Uppsala Primary Health Care project (SUPRIM). Arch Intern Med 2011;171:134-40.

101. Goodwin CL, Forman EM, Herbert JD, et al. A pilot study examining the initial effectiveness of a brief acceptance-based 
behavior therapy for modifying diet and physical activity among cardiac patients. Behav Modif 2012;36:199-217.

102. Murphy BM, Worcester MU, Higgins R0, et al. Reduction in 2-year recurrent risk score and improved behavioral outcomes after participation in the "Beating Heart Problems" self-management program: results of a randomized controlled trial. J Cardiopulm Rehabil Prev 2013;33:220-8.

103. Orth-Gomér K. Behavioral interventions for coronary heart disease patients. Biopsychosoc Med 2012;6:5.

104. Parswani MJ, Sharma MP, lyengar S. Mindfulness-based stress reduction program in coronary heart disease: a randomized control trial. Int J Yoga 2013;6:111-7.

105. Blumenthal JA, Sherwood A, Smith PJ, et al. Enhancing cardiac rehabilitation with stress management training: A randomized, clinical efficacy trial. Circulation 2016;133:1341-50.

106. Roncella A, Pristipino C, Cianfrocca C, et al. One-year results of the randomized, controlled, short-term psychotherapy in acute myocardial infarction (STEP-IN-AMI) trial. Int J Cardiol 2013;170:132-9.

107. Lespérance F, Frasure-Smith N, Koszycki D, et al. Effects of citalopram and interpersonal psychotherapy on depression in patients with coronary artery disease the Canadian Cardiac Randomized Evaluation of Antidepressant and Psychotherapy Efficacy (CREATE) trial. JAMA 2007;297;367-79.

108. Takagi H, Ando T, Umemoto T, ALICE (All-Literature Investigation of Cardiovascular Evidence) Group. Perioperative depression or anxiety and postoperative mortality in cardiac surgery: a systematic review and meta-analysis. Heart Vessels 2017;32:1458-68.

109. Indja B, Seco M, Seamark R, et al. Neurocognitive and psychiatric issues post cardiac surgery. Heart Lung Circ 2017;26:779-85.

110. Singh A, Agrawal S, Gargya S, et al. Posttraumatic stress disorder after myocardial infarction and coronary artery bypass grafting. Int J Crit Illn Inj Sci 2017;7:84-90.

111. Stoll C, Schelling G, Goetz AE, et al. Health-related quality of life and post-traumatic stress disorder in patients after cardiac surgery and intensive care treatment. J Thorac Cardiovasc Surg 2000;120:505-12.

112. Fink HA, Hemmy LS, MacDonald R, et al. Cognitive outcomes after cardiovascular procedures in older adults: A systematic review [Internet]. Rockville (MD): Agency for Healthcare Research and Quality (US); 2014 Nov 17. Available from http:/www.ncbi.nlm.nih.gov/books/NBK285350/

113. Patel N, Minhas JS, Chung EM. Risk factors associated with cognitive decline after cardiac surgery: A systematic review. Cardiovasc Psychiatry Neurol 2015;2015:370612.

114. Tully PJ, Baune BT, Baker RA. Cognitive impairment before and six months after cardiac surgery increase mortality risk at median 11 year follow-up: a cohort study. International Journal of Cardiology 2013;168:2796-802.

115. Knipp SC, Kahlert P, Jokisch D, et al. Cognitive function after transapical aortic valve implantation: a single-centre study with 3-month follow-up. Interact Cardiovasc Thorac Surg 2013;16:116-22.

116. Nguyen Q, Uminski K, Hiebert BM, et al. Midterm outcomes after postoperative delirium on cognition and mood in patients after cardiac surgery. J Thorac Cardiovasc Surg 2018;155:660-67.

117. Suárez Bagnasco M, Núñez-Gil IJ. Infective endocarditis and thoracic aortic disease: A review on forgotten psychological aspects. World J Cardiol 2017;9:620-28.

118. Ponikowski P, Voors AA, Anker SD, et al. 2016 ESC Guidelines for the diagnosis and treatment of acute and chronic heart failure: The Task Force for the diagnosis and treatment of acute and chronic heart failure of the European Society of Cardiology (ESC)Developed with the special contribution of the Heart Failure
Association (HFA) of the ESC. Eur Heart J 2016;37:2129-2200. Erratum in: Eur Heart J 2016 Dec 30.

119. Sokoreli I, de Vries JJ, Pauws SC, Steyerberg EW. Depression and anxiety as predictors of mortality among heart failure patients: systematic review and meta-analysis. Heart Fail Rev 2016;21:49-63.

120. Wang Y, Hu G. Individual and joint associations of obesity and physical activity on the risk of heart failure. Congest Heart Fail 2010;16:292-9.

121. Gopal DM, Kalogeropoulos AP, Georgiopoulou VV, et al. Cigarette smoking exposure and heart failure risk in older adults: the health, aging, and body composition study. Am Heart J 2012;164:236-42.

122. Awtry EH, Philippides GJ. Alcoholic and cocaine-associated cardiomyopathies. Prog Cardiovasc Dis 2010;52:289-99.

123. Müller-Tasch T, Löwe B, Lossnitzer N, et al. Anxiety and self-care behaviour in patients with chronic systolic heart failure: A multivariate model. Eur J Cardiovasc Nurs 2018;17:170-7.

124. Hawkins NM, Jhund PS, McMurray JJ, Capewell S. Heart failure and socioeconomic status: accumulating evidence of inequality. Eur J Heart Fail 2012;14:138-46.

125. Borné Y, Engström G, Essén B, Hedblad B. Immigrant status and increased risk of heart failure: the role of hypertension and lifestyle risk factors. BMC Cardiovasc Disord 2012;26;12:20.

126. Betihavas V, Davidson PM, Newton PJ, et al. What are the factors in risk prediction models for rehospitalisation for adults with chronic heart failure? Aust Crit Care 2012;25:31-40.

127. Calvillo-King L, Arnold D, Eubank KJ, et al. Impact of social factors on risk of readmission or mortality in pneumonia and heart failure: systematic review. J Gen Intern Med 2013;28:269-82.

128. Schiffer AA, Smith OR, Pedersen SS, et al. Type D personality and cardiac mortality in patients with chronic heart failure Int $\mathrm{J}$ Cardiol 2010;142:230-5.

129. Pelle AJ, Schiffer AA, Smith OR, et al. Inadequate consultation behavior modulates the relationship between type $\mathrm{D}$ personality and impaired health status in chronic heart failure. Int $\mathrm{J}$ Cardiol 2010;142:65-71.

130. Kupper N, Denollet J, Widdershoven J, Kop WJ. Type D personality is associated with low cardiovascular reactivity to acute mental stress in heart failure patients. Int J Psychophysiol 2013;90:44-9.

131. Widdershoven J, Kessing D, Schiffer A, et al. How are depression and type D personality associated with outcomes in chronic heart failure patients? Curr Heart Fail Rep 2013;10:244-53.

132. Denollet J, Conraads VM. Type D personality and vulnerability to adverse outcomes in heart disease. Cleve Clin J Med 2011;78 Suppl 1:S13-9.

133. DuBois CM, Lopez OV, Beale EE, et al. Relationships between positive psychological constructs and health outcomes in patients with cardiovascular disease: A systematic review. Int J Cardiol 2015;195:265-80.

134. Majani G, Pierobon A, Pinna GD, et al. Additive prognostic value of subjective assessment with respect to clinicalcardiological data in patients with chronic heart failure. Eur J Cardiovasc Prev Rehabil 2011;18:836-42.

135. Cameron J, Gallagher R, Pressler SJ. Detecting and managing cognitive impairment to improve engagement in heart failure selfcare. Curr Heart Fail Rep 2017;14:13-22.

136. Hjelm C, Strömberg A, Arestedt K, Broström A. Association between sleep-disordered breathing, sleep-wake pattern, and cognitive impairment among patients with chronic heart failure. Eur J Heart Fail 2013;15:496-504.

137. Knecht KM, Alosco ML, Spitznagel MB, et al. Sleep apnea and cognitive function in heart failure. Cardiovasc Psychiatry Neurol 2012;2012:402079. 
138. Keteyian SJ, Squires RW, Ades PA, Thomas RJ. Incorporating patients with chronic heart failure into outpatient cardiac rehabilitation: practical recommendations for exercise and self-care counselinga clinical review. J Cardiopulm Rehabil Prev 2014;34:223-32.

139. Wingham J, Harding G, Britten N, Dalal H. Heart failure patients' attitudes, beliefs, expectations and experiences of self-management strategies: a qualitative synthesis. Chronic Illn 2014;10:135-54.

140. Wakefield BJ, Boren SA, Groves PS, Conn VS. Heart failure care management programs: a review of study interventions and metaanalysis of outcomes. J Cardiovasc Nurs 2013;28:8-19.

141. Andrikopoulou E, Abbate K, Whellan DJ. Conceptual model for heart failure disease management. Can J Cardiol 2014;30:304-11.

142. Pandor A, Thokala P, Gomersall T, et al. Home telemonitoring or structured telephone support programmes after recent discharge in patients with heart failure: systematic review and economic evaluation. Health Technol Assess 2013;17:1-207.

143. Jaarsma T, Brons M, Kraai I, et al. Components of heart failure management in home care; a literature review. Eur J Cardiovasc Nurs 2013;12:230-41.

144. Kwekkeboom KL, Bratzke LC. A Systematic review of relaxation, meditation, and guided imagery strategies for symptom management in heart failure. J Cardiovasc Nurs 2016;31:457-68.

145. Ditewig JB, Blok H, Havers J, van Veenendaal H. Effectiveness of self-management interventions on mortality, hospital readmissions, chronic heart failure hospitalization rate and quality of life in patients with chronic heart failure: a systematic review. Patient Educ Couns 2010;78:297-315.

146. Molloy GJ, 0'Carroll RE, Witham MD, McMurdo ME. Interventions to enhance adherence to medications in patients with heart failure: a systematic review. Circ Heart Fail 2012;5:126-33.

147. Samartzis L, Dimopoulos S, Tziongourou M, Nanas S. Effect of psychosocial interventions on quality of life in patients with chronic heart failure: a meta-analysis of randomized controlled trials. Card Fail 2013;19:125-34.

148. Dekker RL. Patient perspectives about depressive symptoms in heart failure: a review of the qualitative literature. J Cardiovasc Nurs 2014;29:E9-15.

149. Rustad JK, Stern TA, Hebert KA, Musselman DL. Diagnosis and Treatment of Depression in Patients With congestive Heart Failure: A Review of the Literature. Prim Care Companion CNS Disord 2013;15:1-38.

150. Woltz PC, Chapa DW, Friedmann E, et al. Effects of interventions on depression in heart failure: a systematic review. Heart Lung 2012;41:469-83.

151. Stamp KD, Machado MA, Allen NA. Transitional care programs improve outcomes for heart failure patients: an integrative review. J Cardiovasc Nurs 2014;29:140-54.

152. Baker DW, DeWalt DA, Schillinger D, et al. "Teach to goal”: theory and design principles of an intervention to improve heart failure self-management skills of patients with low health literacy. J Health Commun 2011;16:73-88.

153. Grady KL, de Leon CF, Kozak AT, et al. Does self-management counseling in patients with heart failure improve quality of life? Findings from the Heart Failure Adherence and Retention Trial (HART). Qual Life Res 2014;23:31-8.

154. Jiang Y, Shorey S, Seah B, et al. The effectiveness of psychological interventions on self-care, psychological and health outcomes in patients with chronic heart failure-A systematic review and metaanalysis. Int J Nurs Stud 2018;78:16-25.

155. Tsuchihashi-Makaya M, Matsuo H, Kakinoki S, et al. Home-based disease management program to improve psychological status in patients with heart failure in Japan. Circ J 2013;77:926-33.
156. Clark AP, McDougall G, Riegel B, et al. Health status and self-care outcomes after an education-support intervention for people with chronic heart failure. J Cardiovasc Nurs 2015;30:S3-13.

157. Spatola CF, Cocchieri A, De Marinis MG, et al. Educational interventions in patients with heart failure: a review of the literature. Ig Sanita Pubbl 2013;69:557-74.

158. Lee KS, Lennie TA, Dunbar SB, et al. The association between regular symptom monitoring and self-care management in patients with heart failure. J Cardiovasc Nurs 2015;30:145-51.

159. Fredericks S, Beanlands H, Spalding K, Da Silva M. Effects of the characteristics of teaching on the outcomes of heart failure patient education interventions: a systematic review. Eur J Cardiovasc Nurs 2010;9:30-7.

160. Huffman JC, Mastromauro CA, Beach SR, et al. Collaborative care for depression and anxiety disorders in patients with recent cardiac events: the Management of Sadness and Anxiety in Cardiology (MOSAIC) randomized clinical trial. JAMA Intern Med 2014;174:927-35.

161. Jaarsma T, Lesman-Leegte I, Hillege HL, et al. Depression and the usefulness of a disease management program in heart failure: insights from the $\mathrm{COACH}$ (Coordinating study evaluating Outcomes of Advising and Counseling in Heart failure) study. J Am Coll Cardiol 2010;55:1837-43.

162. Jaarsma T, Brons M, Kraai I, et al. Components of heart failure management in home care; a literature review. Eur J Cardiovasc Nurs 2013;12:230-41.

163. Köberich S, Lohrmann C, Mittag 0, Dassen T. Effects of a hospitalbased education programme on self-care behaviour, care dependency and quality of life in patients with heart failure-a randomised controlled trial. J Clin Nurs 2015;24:1643-55.

164. Smith CE, Piamjariyakul U, Wick JA, et al. Multidisciplinary group clinic appointments: the Self-Management and Care of Heart Failure (SMAC-HF) trial. Circ Heart Fail 2014;7:888-94.

165. Lundgren J, Andersson G, Johansson P. Can cognitive behaviour therapy be beneficial for heart failure patients? Curr Heart Fail Rep 2015;12:166-72.

166. Ghanbari-Firoozabadi M, Rahimianfar AA, Reza Vafaii Nasab M, et al. A study of the effect of cardiac rehabilitation on heart failure patients' life quality. J Med Life 2014;15;7:51-4.

167. Tully PJ, Selkow T, Bengel J, Rafanelli C. A dynamic view of comorbid depression and generalized anxiety disorder symptom change in chronic heart failure: the discrete effects of cognitive behavioral therapy, exercise, and psychotropic medication. Disabil Rehabil 2015;37:585-92.

168. Smith L. Evaluation and treatment of depression in patients with heart failure. J Am Acad Nurse Pract 2010;22:440-8.

169. Jeyanantham K, Kotecha D, Thanki D, et al. Effects of cognitive behavioural therapy for depression in heart failure patients: a systematic review and meta-analysis. Heart Fail Rev 2017;22731-41.

170. Baghianimoghadam MH, Shogafard G, Sanati HR, et al. Application of the health belief model in promotion of self-care in heart failure patients. Acta Med Iran 2013;51:52-8

171. Dubois CM, Beach SR, Kashdan TB, et al. Positive psychological attributes and cardiac outcomes: associations, mechanisms, and interventions. Psychosomatics 2012;53:303-18.

172. Jayadevappa R, Johnson JC, Bloom BS, et al. Effectiveness of transcendental meditation on functional capacity and quality of life of African Americans with congestive heart failure: A randomized control study. Ethn Dis 2007;17:72-7.

173. Sullivan MJ, Wood L, Terry J, et al. The Support, Education, and Research in Chronic Heart Failure Study (SEARCH): 
A mindfulness-based psychoeducational intervention improves depression and clinical symptoms in patients with chronic heart failure Am Heart J 2009;157:84-90.

174. Younge JO, Wery MF, Gotink RA, et al. Web-based mindfulness intervention in heart disease: a randomized controlled trial. PLoS One 2015;10:e0143843.

175. Piotrowicz E, Piepoli MF, Jaarsma T, Lambrinou E, Coats AJ, Schmid JP, Corrà U, Agostoni P, Dickstein K, Seferović PM, Adamopoulos S, Ponikowski PP. Telerehabilitation in heart failure patients: The evidence and the pitfalls. Int J Cardiol 2016 0ct 1;220:408-13.

176. Di Lenarda A, Casolo G, Gulizia MM, et al. [ANMCO/SIC/SIT Consensus document: The future of telemedicine in heart failure]. G Ital Cardiol 2016;17:491-507. [Article in Italian].

177. Psychosocial Outcomes Workgroup of the Nursing and Social Sciences Council of the International Society for Heart and Lung Transplantation. Cupples S, Dew MA, Grady KL, et al. Report of the Psychosocia Outcomes Workgroup of the Nursing and Social Sciences Council of the International Society for Heart and Lung Transplantation: present status of research on psychosocial outcomes in cardiothoracic transplantation: review and recommendations for the field. J Heart Lung Transplant 2006;25:716-25.

178. Mehra MR, Canter CE, Hannan MM, et al. The 2016 International Society for Heart Lung Transplantation listing criteria for heart transplantation: A 10-year update. J Heart Lung Transplant 2016;35:1-23.

179. Sánchez R, Baillés E, Peri JM, et al. Cross-sectional psychosocial evaluation of heart transplantation candidates. Gen Hosp Psychiatry 2014;36:680-5.

180. Sánchez R, Baillès E, Peri JM, et al. Assessment of psychosocial factors and predictors of psychopathology in a sample of heart transplantation recipients: a prospective 12-month follow-up. Gen Hosp Psychiatry 2016;38:59-64.

181. Dobbels F, Vanhaecke J, Dupont L, et al. Pretransplant predictors of posttransplant adherence and clinical outcome: an evidence base for pretransplant psychosocial screening. Transplantation 2009;87:1497-504.

182. Farmer SA, Grady KL, Wang E, et al. Demographic, psychosocial, and behavioral factors associated with survival after heart transplantation. Ann Thorac Surg 2013;95:876-83.

183. Spaderna H, Mendell NR, Zahn D, et al. Social isolation and depression predict 12-month outcomes in the "waiting for a new heart study". J Heart Lung Transplant 2010;29:247-54.

184. Sirri L, Magelli C, Grandi S. Predictors of perceived social support in long-term survivors of cardiac transplant: The role of psychological distress, quality of life, demographic characteristics and clinical course. Psychol Health 2011;26:77-94.

185. Spaderna H, Zahn D, Schulze Schleithoff S, et al. Depression and disease severity as correlates of everyday physical activity in heart transplant candidates. Transpl Int 2010;23:813-22.

186. Chenyu YE, Zhuang Y, Zhang Y, et al. Anxiety, depression, and associated factors among inpatients waiting for heart transplantation. Shangai Arch Psychiat 2013;25:165-73.

187. Foster ER, Cunnane KB, Edwards DF, et al. Executive dysfunction and depressive symptoms associated with reduced participation of people with severe congestive heart failure. Am J Occup Ther 2011;65:306-13.

188. Grandi S, Sirri L, Tossani E, et al. Executive dysfunction and depressive symptoms associated with reduced participation of people with severe congestive heart failure. Am J Occup Ther 2011;65:306-13.
189. Harris J, Heil JS. Managing depression in patients with advanced heart failure awaiting transplantation. Am J Health Syst Pharm 2013;70:867-73.

190. Dew MA, Rosenberger EM, Myaskovsky L, et al. Depression and anxiety as risk factors for morbidity and mortality after organ transplantation: A systematic review and meta-analysis. Transplantation 2015;100:988-1003.

191. Favaro A, Gerosa G, Caforio ALP et al. Posttraumatic stress disorder and depression in heart transplantation recipients: the relationship with outcome and adherence to medical treatment. General Hospital Psychiatry 2011;33:1-7.

192. Grandi S, Sirri L, Tossani E, Fava GA. Psychological characterization of demoralization in the setting of heart transplantation. J Clin Psychiatry 2011;72:648-54.

193. Ruzyczka EW, Milaniak I, Przybyłowski P, et al. Depression and quality of life in terms of personal resources in heart transplant recipients. Transplantation Proceedings 2011;43:3076-81.

194. Pérez San Gregorio MA, Martìn Rodrìguez A, Pérez Bernal J. Psychological differences of patients and relatives according to post-transplantation anxiety. Span J Psychol 2008;11:250-58.

195. Weidner G, Spaderna H. The role of the Heart Failure Survival Score and psychosocial stress in predicting event-free survival in patients referred for heart transplantation. J Heart Lung Transplant 2012;31:436-38.

196. White-Williams C, Grady KL, Myers S, et al. The relationships among satisfaction with social support, quality of life, and survival 5 to 10 years after heart transplantation. J Cardiovasc Nurs 2013;28:407-16.

197. Burker EJ, Madan A, Evon D, et al. Educational level, coping, and psychological and physical aspects of quality of life in heart transplant candidates. Clin Transplant 2009;23:233-40.

198. Ye C, Zhuang Y, Zhang Y, et al. Anxiety, depression, and associated factors among inpatients waiting for heart transplantation. Shanghai Arch Psychiatry 2013;25:165-73.

199. Abbey SE, De Luca E, Mauthner OE, et al. Qualitative interviews vs standardized self-report questionnaires in assessing quality of life in heart transplant recipients. Heart Lung Transplant 2011;30:204-10.

200. Grady KL, Wang E, White-Williams C et al. Factors associated with stress and coping at 5 and 10 years after heart transplantation. J Heart Lung Transplant 2013;32:437-46.

201. Denollet J, Holmes RV, Vrints CJ, et al. Unfavorable outcome of heart transplantation in recipients with type D personality. J Heart Lung Transplant 2007;26:152-58.

202. Pedersen SS, Holkamp PG, Caliskan K, et al. Type D personality is associated with impaired health-related quality of life 7 years following heart transplantation. J Psychosom Res 2006;61:791-5.

203. Burker EJ, Evon DM, Marroquin Loiselle M, et al. Coping predicts depression and disability in heart transplant candidates. J Psychosom Res 2005;59:215-22.

204. Germani G, Lazzaro S, Gnoato F et al. Nonadherent behaviors after solid organ transplantation. Transplant Proc 2011;43:318-23.

205. Korb-Savoldelli V, Sabatier B, Gillaizeau F, et al. Non-adherence with drug treatment after heart or lung transplantation in adults: a systematic review. Patient Educ Couns 2010;81:148-54.

206. Conway A, Schadewaldt V, Clark R et al. The psychological experiences of adult heart transplant recipients: a systematic review and meta-summary of qualitative findings. Heart Lung 2013;42:449-55.

207. Grady KL, Wang E, White-Williams C, et al. Factors associated with stress and coping at 5 and 10 years after heart transplantation. J Heart Lung Transplant 2013;32:437-46. 
208. Mapelli D, Bardi L, Mojoli M, et al. Neuropsychological profile in a large group of heart transplant candidates. PLoS One 2011;6:e28313.

209. Samelson-Jones E, Mancini DM, Shapiro PA. Cardiac transplantation in adult patients with mental retardation: do outcomes support consensus guidelines? Psychosomatics 2012;53:133-8.

210. Bürker BS, Gude E, Gullestad L, et al. Cognitive function among long-term survivors of heart transplantation. Clin Transplant 2017;31.

211. Conway A, Schadewaldt RC, Ski CR, et al. The effectiveness of non-pharmacological interventions in improving psychological outcomes for heart transplant recipients: A systematic review. Eur J Cardiovasc Nurs 2014;13:108-15.

212. Gross CR, Kreitzer MJ, Thomas W, et al. Mindfulness-based stress reduction for solid organ transplant recipients: a randomized controlled trial. Altern Ther Health Med 2010;16:30-8.

213. Heilmann C, Kuijpers N, Beyersdorf F, et al. Supportive psychotherapy for patients with heart transplantation or ventricular assist devices. Eur J Cardiothorac Surg 2011;39:44-50.

214. Siwiska J, Lesiak-Kalukin M, Przybylowski P, Sadowski J. Health behavior of patients after heart transplantation as an indicator of patient compliance. Transplant Proc 2011;43:3086-88.

215. Roussel MG, Gorham N, Wilson L, Mangi AA. Improving recovery time following heart transplantation: the role of the multidisciplinary health care team. J Multidiscip Healthc 2013:6;293-302.

216. Sadala MLA, Stolf NG, Bocchi ED, Viggiani Bicudo MA. Caring for heart transplant recipients: The lived experience of primary caregivers. Heart Lung 2013;42:120-5.

217. Botha P, Peaston R, White $\mathrm{K}$ et al. Smoking after cardiac transplantation. Am J Transplan 2008;8:866-71.

218. Brouwers C, Denollet J, de Jonge N et al. Patient-reported outcomes in left ventricular assist device therapy: a systematic review and recommendations for clinical research and practice. Circ Heart Fail 2011;4:714-23.

219. Maciver J, Ross HJ. Quality of life and left ventricular assist device support. Circulation 2012;126:866-74.

220. Yost G, Bhat G, Mahoney E, Tatooles A. Reduced anxiety and depression in patients with advanced heart failure after left ventricular assist device implantation. Psychosomatics 2017;58:406-14.

221. Hallas C, Banner NR, Wray J. A qualitative study of the psychological experience of patients during and after mechanical cardiac support. J Cardiovasc Nurs 2009;24:31-9.

222. Balestroni G, Omarini G, Omarini P, et al. [Assistenza ventricolare meccanica: quale impatto emozionale sul paziente?] Monaldi Arch Chest Dis 2014;82:55-60 [Article in Italian].

223. Brouwers C, Denollet J, de Jonge N, et al. Patient-reported outcomes in left ventricular assist device therapy: a systematic review and recommendations for clinical research and practice. Circ Heart Fail 2011;4:714-23.

224. Brouwers C, Denollet J, Caliskan K, et al. Psychological distress in patients with a left ventricular assist device and their partners: An exploratory study. Eur J Cardiovasc Nurs 2015;14:53-62.

225. Mapelli D, Cavazzana A, Cavalli C et al. Clinical psychological and neuropsychological issues with left ventricular assist devices (LVADs). Ann Cardiothoracic Surg 2014;3:480-9.

226. Brouwers C, Caliskan K, de Jonge N, et al. A comparison of the health status and psychological distress of partners of patients with a left ventricular assist device versus an implantable cardioverter defibrillator: a preliminary study. Heart Lung $2015 ; 44: 27-32$.
227. Casida JM, Davis JE, Brewer RJ, et al. Sleep and daytime sleepiness of patients with left ventricular assist devices: a longitudinal pilot study. Progr Transplant 2011;21:131-36.

228. Casida JM, Brewer RJ, Smith C, Davis JE. An exploratory study of sleep quality, daytime function, and quality of life in patients with mechanical circulatory support. Int J Artif Organs 2012;35:531-37.

229. Fendler TJ, Spertus JA, Gosch KL, et al. Incidence and predictors of cognitive decline in patients with left ventricular assist devices. Circ Cardiovasc Qual Outcomes 2015;8:285-91.

230. Hudson MM, Haines ME, Schwann TA, et al. Cognitive improvement after left ventricular assist device implant. J Cardiac Fail 2015;21:S1-S142.

231. Petrucci RJ, Wright $S$, Naka Y et al. Neurocognitive assessment in advanced heart failure patients receiving continuous-flow left ventricular assist devices. J Hearth Lung Transplant 2009;28:542-9.

232. Petrucci RJ, Rogers JG, Blue L et al. Neurocognitive function in destination therapy patients receiving continuous-flow vs pulsatile-flow left ventricular assist device support. J Heart Lung Transplant 2012;31:27-36.

233. Simoni D, Rafanelli M, Ungar A, et al. Neurocognitive profile of patients with continuous flow left ventricular assist device. Monaldi Arch Chest Dis 2014;82:75-9.

234. English ML Speed J. Effectiveness of acute inpatient rehabilitation after left ventricular assist device placement. Am J Phys Med Rehabil 2013;92:621-6.

235. Karapolat H, Engin C, Eroglu M et al. Efficacy of the cardiac rehabilitation program in patients with end-stage heart failure, heart transplant patients, and left ventricular assist device recipients. Transplant Proc 2013;45:3381-5.

236. Heilmann C, Kuijpers N, Beyersdorf F, et al. Supportive psychotherapy for patients with heart transplantation or ventricular assist devices. Eur J Cardiothorac Surg 2011;39:e44-50.

237. Heilmann C, Kuijpers N, Beyersdorf F, et al. Does listing for heart transplant for longer than 30 days before ventricular assist device implantation influence utilization of psychotherapeutic support and outcome? Eur J Cardiothorac Surg 2012;41:1371-6.

238. Corrà U, Pistono M, Piepoli MF, Giannuzzi P. Ventricular assist device patients on the horizon of cardiovascular prevention and rehabilitation. Can we convert challenges into opportunities? Eur J Prev Cardiol 2012;19:490-3.

239. Pistono M, Corrà U, Gnemmi M, et al. Cardiovascular prevention and rehabilitation for patients with ventricular assist device from exercise therapy to long-term therapy. Part II: long-term therapy. Monaldi Arch Chest Dis 2011;76:136-45.

240. Kugler C, Malehsa D, Schrader E, et al. A multi-modal intervention in management of left ventricular assist device outpatients: dietary counselling, controlled exercise and psychosocial support. Eur J Cardiothorac Surg 2012;42:1026-32.

241. Pedersen SS, Spindler H, Johansen JB, et al. Correlates of patient acceptance of the cardioverter defibrillator: cross-validation of the Florida patient acceptance survey in Danish patients. Pacing Clin Electrophysiol 2008;31:1168-77.

242. Melendugno A, Volpe B, Favaro A, et al. [ICD e aspetti psicologici, psicopatologici e di qualità della vita: revisione della letteratura ed esperienza dell'Azienda Ospedaliera di Padova]. Giornale Ital Aritmol Cardiostimol 2010;13(1) [Article in Italian].

243. Versteeg H, Starrenburg A, Denollet J, et al. Monitoring device acceptance in implantable cardioverter defibrillator patients using the Florida patient accepatance survey. PACE 2012;35:283-93.

244. Habibović M, Denollet J, Pedersen SS; on behalf of the WEBCARE investigators. Posttraumatic stress and anxiety in patients with an implantable cardioverter defibrillator: Trajectories and vulnerability factors. Pacing Clin Electrophysiol 2017;40:817-823. 
245. Manzoni GM, Castelnuovo G, Compare A, et al. Psychological effects of implantable cardioverter defibrillator shocks. A review of study methods. Front Psychol 2015;6:39.

246. Shalaby AA, Brumberg GE, Pointer L, et al. Depression and outcome among veterans with implantable cardioverter defibrillattors with or without cardiac resynchronization terapy capability. PACE 2014;37:994-1001.

247. Schulz SM, Massa C, Grzbiela A, et al. Implantable cardioverter defibrillator shocks are prospective predictors of anxiety. Heart Lung 2013;42:105-11.

248. Hoogwegt MT, Kupper N, Theuns DA, et al. Undertreatment of anxiety and depression in patients with an implantable cardioverter-defibrillator: impact on health status. Health Psychol 2012;31:745-53.

249. Lang S, Becker R, Wilke S, et al. Anxiety disorders in patients with implantable cardioverter defibrillators: Frequency, Course, predictors, and patients' requests for treatment. PACE 2014;37:35-47.

250. Walker RL, Campbell KA, Sears SF, et al. Women and the implantable cardioverter defibrillator: a lifespan perspective on key psychosocial issues. Clin Cardiol 2004;27:543-6.

251. Sowell LV, Kuhl EA, Sears SF, et al. Device implant technique and consideration of body image: specific procedures for implantable cardioverter defibrillators in female patients. J Womens Health (Larchmt) 2006;15:830-5.

252. Sears SF, Rosman L, Sasaki S, et al. Defibrillator shocks and their impact on objective and subjective patient outcomes: Results from the PainFree SST clinical trial. Heart Rhythm 2017; pii: S1547-5271(17)31460-1.

253. Sears SF, Hauf JD, Kirian K, et al Postraumatic stress and the implantable cardioverter-defibrillator patient: What the electrophysiologist needs to know. Circ Arrhythm Electrophysiol 2011;4:242-50.

254. Pedersen SS, Schiffer AA. The distressed (Type D) personality. A risk marker for poor health outcomes in ICD patients. Herzschrittmacherther Elektrophysiol 2011;22:181-8.

255. Starrenburg AH, Kraaier K, Pedersen SS, et al. Association of psychiatric history and type $\mathrm{D}$ personality with symptoms of anxiety, depression, and health status prior to ICD implantation. Int J Behav Med 2013;20:425-33.

256. Habibović M, Broers E, Heumen D, et al. Optimism as predictor of patient-reported outcomes in patients with an implantable cardioverter defibrillator (data from the WEBCARE study). Gen Hosp Psychiatry 2017;50:90-5.

257. Hałas K, Krzyżanowski K, Krzyżanowska E, et al. Cognitive impairment after appropriate implantable cardioverterdefibrillator therapy for ventricular fibrillation. Kardiol Pol 2014;72:134-9.

258. Jama A, Rabinstein A, Hodge D, et al. Cardiac device complications in the cognitively impaired. Pacing Clin Electrophysiol 2013;36:1061-7.

259. Pedersen SS, Knudsen C, Dilling $\mathrm{K}$, et al. Living with an implantable cardioverter defibrillator: patients' preferences and needs for information provision and care options. Europace 2017;19:983-90.

260. Habibović M, Burg MM, Pedersen SS. Behavioral intervention in patients with an implantable cardioverter defibrillator: lessons learned and where to go from here? Pacing Clin Electrophysiol 2013;36:578-90.

261. Maia C0, Braga AA, Soares-Filho G, et al. Efficacy of cognitive behavioral therapy in reducing psychiatric symptoms in patients with implantable cardioverter defibrillator: an integrative review. Braz J Med Biol Res 2014;47:265-72.
262. Lewin RJ, Coulton S,Frizelle DJ, et al. A brief cognitive behavioural preimplantation and rehabilitation programme for patients receiving an implantable cardioverter-defibrillator improves physical health and reduces psychological morbidity and unplanned readmissions. Heart 2009;95:63-9.

263. Salmoirago-Blotchera E, Crawfordb SL, Carmodyb J, et al. Phonedelivered mindfulness training for patients with implantable cardioverter defibrillators: Results of a pilot randomized controlled trial. Ann Behav Med 2013;46:243-50.

264. Toise CF, Sears SF, Schoenfeld MS, et al. Psychosocial and cardiac outcomes of yoga for ICD patients: A randomized clinical control trial. Pacing Clin Electrophysiol 2014;37:48-62.

265. Dunbar S, Langberg J, Reilly CM, et al. Effect of a psychoeducational intervention on depression, anxiety and health resource use in implantable cardioverter defibrillator patients. Pacing Clin Electrophysiol 2009;32:1259-71.

266. Kikkenborg Berg S, Moons P, Zwisler A, et al. Phantom shocks in patients with implantable cardioverter defibrillator: results from a randomized rehabilitation trial (COPE-ICD). Europace 2013;15:1463-7.

267. Pedersen S, Spek V, Theuns D, et al. Rationale and design of WEBCARE: A randomized, controlled, web-based behavioral intervention trial in cardioverter-defibrillator patients to reduce anxiety and device concerns and enhance quality of life. Trials 2009;10:120.

268. Matura LA, Carroll DL. Human responses to pulmonary arterial hypertension: review of the literature. J Cardiovasc Nurs 2010;25:420-7.

269. Vanhoof JMM, Delcroix M, Vandevelde E, et al. Emotional symptoms and quality of life in patients with pulmonary arterial hypertension. J Heart Lung Transplant 2014;33:800-8.

270. Mathai SC, Suber T, Khair RM, et al. Health-related quality of life and survival in pulmonary arterial hypertension. Ann Am Thorac Soc 2016;13:31-9.

271. Löwe B, Gräfe K, Ufer C, et al. Anxiety and depression in patients with pulmonary hypertension. Psychosom Med.2004;66:831-6.

272. Wryobeck JM, Lippo G, McLaughlin V, et al. Psychosocial aspects of pulmonary hypertension: a review. Psychosomatics 2007;48:467-75.

273. Verma S, Sahni S, Vijayan VK, Talwar A. Depression in pulmonary arterial hypertension: An undertreated comorbidity. Lung India 2016;33:58-63.

274. Matura LA, McDonough A, Hanlon AL, et al. Sleep disturbance, symptoms, psychological distress, and health-related quality of life in pulmonary arterial hypertension. Eur J Cardiovasc Nurs 2015;14:423-30.

275. Mereles D, Ehlken N, Kreuscher S, et al. Exercise and respiratory training improve exercise capacity and quality of life in patients with severe chronic pulmonary hypertension. Circulation 2006;114:1482-9.

276. Desai SA, Channick RN. Exercise in patients with pulmonary arterial hypertension. J Cardiopulm Rehabil Prev 2008;2812-6.

277. Bussotti M, Gremigni P, Pedretti RFE, et al. Effects of an outpatient service rehabilitation programme in patients affected by pulmonary arterial hypertension: An observational study. Cardiovasc Hematol Disord Drug Targets 2017;17:3-10.

278. Galié N, Humbert M, Vachiery JL, et al. Guidelines for the diagnosis and treatment of pulmonary hypertension. The task force for the diagnosis and treatment of pulmonary hypertension of the European Society of Cardiology (ESC) and the European Respiratory Society (ERS). Endorsed by: Association for Paedriatic and Congenital Cardiology (AEPC), International Society of Heart and Lung Transplantation (ISHLT). Eur Heart J 2015;37:67-119. 
279. Holloway TM, Chesssex C, Grace SL, et al. A call for adult congenital heart disease patient participation in cardiac rehabilitation. Int J Cardiol 2011;150:345-6.

280. Warnes C, Williams RG, Bashore TM, et al. ACC/AHA 2008 Guidelines for the Management of Adults with Congenital Heart Disease: a report of the American College of Cardiology/American Heart Association Task Force on Practice Guidelines (writing committee to develop guidelines on the management of adults with congenital heart disease). Circulation 2008;118:e714-833.

281. Kovacs AH, Saidi AS, Kuhl EA, et al. Depression and anxiety in adult congenital heart disease: predictors and prevalence. Int J Cardiol 2009;137:158-64

282. van Rijen EH, Utens EM, Roos-Hesselink JW, et al. Longitudinal development of psychopathology in an adult congenital heart disease cohort. Int J Cardiol 2005;99:315-23.

283. Callus E, Utens EM, Quadri E, et al. The impact of actual and perceived disease severity on pre-operative psychological wellbeing and illness behaviour in adult congenital heart disease patients. Cardiol Young 2014;24:275-82.

284. Eslami B, Sundin 0, Macassa G, et al. Anxiety, depressive and somatic symptoms in adults with congenital heart disease. J Psychosom Res 2013;74:49-56.

285. Bromberg JI, Beasley PJ, D’Angelo EJ, et al. Depression and anxiety in adults with congenital heart disease: a pilot study. Heart Lung 2003;32:105-10.

286. Cox D, Lewis G, Stuart G, Murphy K. A cross-sectional study of the prevalence of psychopathology in adults with congenital heart disease. J Psychosom Res 2002;52:65-8.

287. Horner T, Liberthson R, Jellinek MS. Psychosocial profile of adults with complex congenital heart disease. Mayo Clin Proc 2000;75:31-6.

288. Cook SC, Valente AM, Maul TM, et al. Shock-related anxiety and sexual function in adults with congenital heart disease and implantable cardioverter-defibrillators. Heart Rhythm 2013;10:805-10.

289. Karsdorp PA, Kindt M, Rietveld S, et al. False heart rate feedback and the perception of heart symptoms in patients with congenital heart disease and anxiety. Int J Behav Med 2009;16:81-8.

290. Moons P, Van Deyk K, De Geest S et al. Is the severity of congenital heart disease associated with the quality of life and perceived health of adult patients? Heart 2005;91:1193-8.

291. Chessa M, De Rosa G, Pardeo, M, et al. Illness understanding in adults with congenital heart disease. Ital Heart J 2005;6:895-9.

292. Callus E, Utens EM, Quadri E, et al. The impact of actual and perceived disease severity on pre-operative psychological wellbeing and illness behaviour in adult congenital heart disease patients. Cardiol Young 2014;24:275-82.

293. van Rijen EH, Utens EM, Roos-Hesselink JW, et al. Psychosocial functioning of the adult with congenital heart disease: a 20-33 years follow-up. Eur Heart J 2003;24:673-83.

294. Moons P, Norekval TM. Is sense of coherence a pathway for improving the quality of life of patients who grow up with chronic diseases? A hypothesis. Eur J Cardiovasc Nurs 2006;5;16-20.

295. van Rijen EH, Utens EM, Roos-Hesselink JW, et al. Medical predictors for psychopathology in adults with operated congenital heart disease. Eur Heart J 2004;25:1605-13.

296. Ferguson M, Kovacs $\mathrm{AH}$. An integrated adult congenital heart disease psychology service. Congenit Heart Dis 2016;11:444-51.

297. Lip GY, Lane DA, Millane TA, Tayebjee MH. Psychological interventions for depression in adolescent and adult congenital heart disease. Cochrane Database Syst Rev 2003:CD004394.

298. Lane DA, Millane TA, Lip GY. Psychological interventions for depression in adolescent and adult congenital heart disease. Cochrane Database Syst Rev 2013;10: CD004372.
299. Guiding principles for the care of older adults with multimorbidity: an approach for clinicians. American Geriatrics Society expert panel on the care of older adults with multimorbidity. J Am Geriatr Soc 2012;60:E1-E25.

300. Singh M, Stewart R, White H. Importance of frailty in patients with cardiovascular disease. Eur Heart J 2014;35:1726-31.

301. Forman D, Wenger N. What do the recent American Heart Association/ American College of Cardiology Foundation Clinical Practice Guidelines tell us about the evolving management of coronary heart disease in older adults? J Geriatr Cardiol 2013;10:123-8.

302. Fried LP, Tangen CM, Walston J, et al. Frailty in older adults: evidence ror a phenotype of frailty. J Gerontol A Biol Med Sci 2001;56:M146-56.

303. Afilo J, Alexander K, Mack M et al. Frailty assessment in the cardiovascular care of older adults. JACC 2014;63:747-62.

304. Fleg J, Forman D, Berra K, et al. Secondary prevention of atherosclerotic cardiovascular disease in older adults. A scientific statement from the American Heart Association. Circulation 2013;128:2422-46.

305. Shamliyan T, Talley KMC, Ramakrishnan R, Kane RL. Association of frailty with survival: a systematic literature review. Ageing Res Rev 2012;12:719-36.

306. Mezuk B, Edwards L, Lohman M, et al. Depression and frailty in later life: a synthetic review. Int J Geriatr Psychiatry 2012;27:879-92.

307. Lohman M, Dumenci L, Mezuk B. Gender differences in the construct overlap of frailty and depression: evidence from the Health and Retirement Study. J Am Geriatr Soc 2014;62:500-5.

308. Thacker EL, Gillett SR, Wadley V et al. The America Heart Association life's simple 7 and incident cognitive impairment: the REasons for Geografic And Racial Differences in Stroke (REGARDS) study. J Am Heart Assoc 2014;3:e000635.

309. Williams J, Alexander K, Morin JF et al. Preoperative anxiety as a predictor of mortality and major morbidity in patients aged $>70$ years undergoing cardiac surgery. Am J Cardiol 2013;111:137-42.

310. Carey IM, Shah SM, Dewilde S, et al. Increased risk of acute cardiovascular events after partner bereavement: a matched cohort study. JAMA Intern Med 2014:174:598-605.

311. Hoogendijk E, Van Hout H, Van der Horst H et al. Do psychosocial resources modify the effects of frailty on functional decline and mortality? Journal of Psychosomatic Research 2014;77:547-51.

312. Menezes A, Lavie C, Forman D, et al. Cardiac rehabilitation in the elderly. Progress in cardiovascular diseases 2014;57:152-9.

313. Forman D, Rich M, Alexander K, et al. Cardiac care for older adults. JACC 2011;57:1801-10.

314. Barnes DE, Santos-Modesitt W, Poelke G, et al. The Mental Activity and eXercise (MAX) trial: a randomized controlled trial to enhance cognitive function in older adults. JAMA Intern Med 2013;173:797-804.

315. Jaarsma T, Beattie JM, Ryder M, et al. Palliative care in heart failure: a position statement from the palliative care workshop of the HF Association of the ESC. Eur J Heart Fail 2009;11:433-43.

316. Wong FKY, Ng AYM, Lee PH, et al. Effects of a transitional palliative care model on patients with end stage heart failure: a randomized controlled trial. Heart 2016;102:1100-8.

317. Gadoud A, Jenkins SMM, Hogg KJ. Palliative care for people with heart failure: summary of current evidence and future direction. Palliat Med 2013;27:822-8.

318. Wordingham SE, Mcllvennan CK, Dionne-Odom N, Swetz K. Complex care option for patients with advanced heart failure approaching end of life. Curr Health Fail Rep 2016;13:20-9.

319. Allen L, Stevenson L, Grady K, et al. Decision making in advanced heart failure. A scientific statement from America Heart Association. Circulation 2012;125:1928-52. 
320. Strömberg A. The situation of caregivers in heart failure and their role in improving patient outcome. Curr Heart Fail Rep 2013;10:270-5.

321. Halm MA. Specific needs, concerns, strategies and advice of caregivers after coronary artery bypass surgery. Heart Lung 2016;45:416-22.

322. Driel AG, de Hosson MJ, Gamel C. Sexuality of patients with chronic heart failure and their spouses and the need for information regarding sexuality. Eur $\mathrm{J}$ Cardiovasc Nurs 2014;13:227-34.

323. Hwang B, Fleischmann KE, Howie-Esquivel J, et al. Caregiving for patients with heart failure: impact of patients families. Am J Crit Care 2011;20:431-41; quiz 442.

324. Whittingham K., Barnes S, Gardiner C. Tools to measure quality of life and carer burden in informal carers of heart failure patients: A narrative review. Palliative Medicine 2013;27:596-607.

325. Kang X, Li Z, Nolan MT. Informal caregivers' experiences of caring for patients with chronic heart failure: systematic review and metasynthesis of qualitative studies. J Cardiovasc Nurs 2011;26:386-94.

326. Nilsson UG, Ivarsson B, Alm-Roijer C, et al. The desire for involvement in healthcare, anxiety and coping in patients and their partners after a myocardial infarction. Eur J Cardiovasc Nurs 2013;12:461-7.

327. Joekes K, Maes S, Warrens M. Predicting quality of life and selfmanagement from dyadic support and overprotection after myocardial infarction. Br J Health Psychol 2007;12:473-89.

328. Burton AM, Sautter JM, Tulsky JA, et al. Burden and well-being among a diverse sample of cancer, congestive heart failure and chronic obstructive pulmonary disease caregivers. J Pain Symptom Manage 2012;44:410-20.

329. Brannström M, Kristofferzon ML, Ivarsson B, et al. Sexual knowledge in patients with a myocardical infarction and their partners. J Cardiovasc Nurs 2014;29:332-9.

330. Halm MA. Age and gender influences on the needs, concerns and strategies of CABG caregivers. Heart Lung 2017;46:159-65.

331. Rolley J, Smith J, Di Giacomo M, et al. The caregiving role following percutaneous coronary intervention. J Clinical Nursing 2010;20:227-35.

332. Reid J, Ski CF, Thompson DR. Psychological interventions for patients with coronary heart disease and their partners: a systematic review. PLoS One 2013;8:e73459.

333. Dalteg T, Benzein E, Fridlund B Malm D. Cardiac disease and its consequences on the partner relationship: a systematic review. J Cardiovasc Nursing 2011,10:140-9.

334. Goldsmith DJ, Bute JJ, Lindholm KA. Patients and partner strategies for talking about lifestyle change following a cardiac event. J Appl Communn Res 2012;40:65-86

335. Bidwell JT, Vellone E, Lyons KS, et al. Caregiver determinants of patient clinical event risk in heart failure. Eur J Cardiovasc Nurs 2017;16:707-14.

336. Rohrbaugh MJ, Shoham V, Cleary AA, et al. Health consequences of partner distress in couples coping with heart failure. Heart Lung 2009;38:298-305.

337. Agren S, Evangelista L, Strömberg A. Do partners of patients with heart failure experience caregiver burden? Eur J Cardiovasc Nurs 2010;9:254-62.

338. Pressler SJ, Gradus-Pizlo I, Chubinski SD, et al. Family caregiver outcomes in heart failure. Am J Crit Care 2009;18:149-59.

339. Rosland AM, Piette JD. Emerging models for mobilizing family support for chronic disease management. A structured review. Chronic Illness 2010;6:7-21.
340. Strömberg A. The situation of caregivers in heart failure and their role in improving patient outcomes. Curr Heart Fail Rep 2013;10:270-5.

341. Chiang LC, Chen WC, Dai YT, Ho YL. The effectiveness of telehealth care on caregiver burden, mastery of stress, and amily function among family caregivers of heart failure patients: a quasi-experimental study. Int J Nurs Stud 2012;49:1230-42

342. Piamjariyakul U, Smith CE, Russell C, et al. The feasibility of a telephone coaching program on heart failure home management for family caregivers. Heart Lung 2013;42:32-9.

343. Myaskovsky L, Posluszny DM, Schulz R, et al. Predictors and outcomes of health-related quality of life in caregivers of cardiothoracic transplant recipients. Am J Transplant 2012;12:3387-97.

344. Sadala ML, Stolf NG, Bocchi EA, Bicudo MA. Caring for heart transplant recipients: the lived experience of primarycaregivers. Heart Lung 2013;42:120-5.

345. Heilmann C, Kuijpers N, Beyersdorf F, et al. Supportive psychotherapy for patients with heart transplantation or ventricular assist devices. Eur J Cardiothorac Surg 2011;39:e44-50.

346. Goetzmann L, Scholz U, Dux R, et al. Attitudes towards transplantation and medication among 121 heart, lung, liver and kidney recipients and their spouses. Swiss Med Wkly 2012;142:w13595.

347. Conway A, Schadewaldt V, Clark R, et al. The psychological experiences of adult heart transplant recipients: A systematic review and meta-summary of qualitative findings. Heart \& Lung 2013;42:449-55.

348. Kaan A, Young QR, Cockell S, Mackay M. Emotional experiences of caregivers of patients with a ventricular assist device. Progr Transplant 2010;20:142-7.

349. Casida J. The lived experiences of spouses of patients with a left ventricular assist device before heart transplantation. Am J Crit Care 2005;14:2.

350. Brouwers C, Denollet J, Caliskan K, et al. Psychological distress in patients with a left ventricular assist device and their partners: An exploratory study. Eur J Cardiovasc Nurs 2015;14:53-62.

351. Stajduhar K, Funk L, Toye C, et al. Part 1: Home-based family caregiving at the end of life: a comprehensive review of published quantitative research (1998-2008). Palliat Med 2010;24:573-93.

352. Penrod J, Hupcey JE, Baney BL, Loeb SJ. End-of-life caregiving trajectories. Clin Nurs Res 2011;20:7-24.

353. Imes CC, Dougherty CM, Pyper G, Sullivan MD. Descriptive study of partners' experiences of living with severe heart failure. Heart Lung 2011;40:208-16.

354. Williams SW, Williams CS, Zimmerman S, et al. Emotional and physical health of informal caregivers of residents at the end of life: the role of social support. J Gerontol B Psychol Sci Soc Sci 2008;63:S171-83.

355. Sautter JM, Tulsky JA, Johnson KS, et al. Caregiver experience during advanced chronic illness and last year of life. J Am Geriatr Soc 2014;62:1082-90.

356. Burton AM, Sautter JM, Tulsky JA, et al. Burden and well-being among a diverse sample of cancer, congestive heart failure, and chronic obstructive pulmonary disease caregivers. J Pain Symptom Manage 2012;44:410-20.

357. Bekelman DB, Nowels CT, Retrum JH, et al. Giving voice to patients' and family caregivers' needs in chronic heart failure: implications for palliative care programs. J Palliat Med 2011;14:1317-24.

358. Garlo K, O'Leary JR, Van Ness PH, Fried TR. Burden in caregivers of older adults with advanced illness. J Am Geriatr Soc 2010;58:2315-22. 
359. Janssen DJ, Spruit MA, Wouters EF, Schols JM. Family caregiving in advanced chronic organ failure. J Am Med Dir Assoc 2012;13:394-9.

360. Yeh PM, Bull M. Use of the resiliency model of family stress, adjustment and adaptation in the analysis of family caregiver reaction among families of older people with congestive heart failure. Int J Older People Nurs 2012;7:117-26.

361. Adelman RD, Tmanova LL, Delgado D, et al. Caregiver burden. JAMA 2014;311:1052-9.
362. Fried TR, Bradley EH, O'Leary JR, Byers AL. Unmet desire for caregiver-patient communication and increased caregiver burden. J Am Geriatr Soc 2005;53:59-65.

363. Retrum JH, Nowels CT, Bekelman DB. Patient and caregiver congruence: the importance of dyads in heart failure care. J Cardiovasc Nurs 2013;28:129-36.

364. Buck HG, Kitko L, Hupcey E. Dyadic heart failure care types qualitative evidence for a novel typology. J Cardiovasc Nursing 2013;28:E37-46. 